RESEARCH PAPER RP1344

Part of Journal of Research of the National Bureau of Standards, Volume 25, November 1940

\title{
STANDARD ELECTRODYNAMIC WATTMETER AND AC-DC TRANSFER INSTRUMENT
}

\author{
By John H. Park and Arthur B. Lewis
}

\section{ABSTRACT}

A description is given of the design and construction of the standard instrument used at the National Bureau of Standards in testing wattmeters and watthour meters.

The investigation to determine the accuracy of this instrument for alternatingcurrent testing at frequencies up to 2,000 cycles per second is described and the results are given.

\section{CONTENTS}

I. Introduction...

II. Design and construction

1. Criteria of design

2. General features of design

3. Details of design and construction . . . . .

(a) Supporting framework

(b) Fixed coils

(c) Moving system

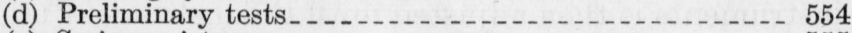

(e) Series resistor

(f) Shielding .

(g) Wattmeter constants......

(1) Fixed coils

(2) Moving system

III. Performance tests _._.

1. Direct-current accuracy _._.

2. Analysis of ac-de errors

3. Errors depending on $E$ or $I$ separately- " $\Delta \alpha " \ldots$

(a) Interaction between parts of voltage circuit........ 563

(b) Magnetic impurities in the moving system ....... 563

(c) Induced and capacitance currents in the moving system 564

4. Errors depending upon $E I$ - test at unity power-factor

(a) Method . .

(b) Procedure

(c) Results

5. Errors depending upon phase angle $\theta$-tests at zero powerfactor

(a) At 60 cycles per second, using quadrant electrometer.- 569

(1) Method..... 569

(2) Procedure

(3) Results

(b) At high frequencies, using eapacitance load........ 573

(1) Method and procedure..... 573

(2) Derivation of equation..... 574

(3) Results . . .

IV. Summary

V. Appendix I. Computation of the effect of variation in wattmeter sensitivity .

VI. Appendix II. Phase difference between the fixed-coil current and the quadrant voltage on the electrometer and the relation of this phase difference to $\theta$, the phase angle between $E$ and $I$................. 


\section{INTRODUCTION}

The basic units for electrical measurements are maintained at the National Bureau of Standards by the use of standard cells and standard resistors. The corrections to be applied to the indications of d-c measuring instruments can therefore be readily and accurately determined by using secondary standards, which have been directly compared with these primary standards, in conjunction with potentiometers and volt boxes. Since the primary standards are maintained by means of d-c measurements, the determination of the corrections to be applied to the indications of a-c instruments must involve at some point the use of a secondary standard or transfer instrument. This transfer instrument must be such that its reading or indication is the same with direct current as with alternating current, or differs by a known amount. The standard instrument is calibrated ${ }^{1}$ on reversed direct current ${ }^{2}$ and this calibration is then transferred to its a-c indications, hence the name.

Such transfer instruments are used in two separate and distinct kinds of tests: (1) in the transfer testing of a-c ammeters, voltmeters, and wattmeters which are of types that can be used on either alternating or direct current, and (2) in the straight testing with alternating current of voltmeters, ammeters, wattmeters, and watthour meters of types that are not suitable for use on direct current. In making the transfer test, the instrument under test is first tested, or calibrated, using the average of the reversed d-c values. The instrument under test and the standard transfer instrument are then so connected as to respond to the same current, voltage, or power. The current on both instruments is then adjusted until the instrument under test comes to the desired scale point and the standard instrument is read. A series of readings, using alternately direct and alternating current, is obtained, and the difference between the mean of the readings obtained with alternating current and that of those with direct current is computed from these data. This procedure very completely eliminates all sources of error-such as heating, shift of zero, and reading error of either instrument-and leaves in the net difference only those errors which arise from sources such as inductance, capacitance, and eddy currents, in which the effect on alternating current differs from that on direct current. The transfer instruments have been carefully studied and any such effects in them are small and definite and can readily be allowed for, so that the net error of the instrument under test on alternating current relative to its performance on direct current is thus determined.

In a straightforward test with alternating current the transfer instrument is calibrated by applying reversed direct current to it alone. It is then used as a standard, and the readings of the instrument under test are compared with it, using alternating current. The standard transfer instrument is calibrated on reversed direct current before and after it is compared at any scale point with the instrument under test. This procedure has to be used when the a-cinstrument is of such nature

\footnotetext{
1 "Calibrate" as used in this paper means the determination of the relation between the indications of, for example, a wattmeter and the true watts.

2 The expression "reversed direct current" is used to designate the regular procedure in the use of instruments of this kind on direct current in order to avoid error caused by the local magnetic field. For example, in using an electrodynamic wattmeter on direct current, two readings are taken, the direction of current flow through the instrument being reversed before taking the second reading. The mean of the two readings gives a result independent of the local magnetic field.
} 
that it does not respond to direct current, and with all instruments the range of which exceeds the range $(10 \mathrm{amp}$ and $300 \mathrm{v})$ of the standard transfer instruments. In this latter case instrument transformers must be used to extend the range of the transfer instrument. It may be noted that any self-heating or shift of zero which occurs in the instrument under test during the course of this straight a-c test will be included in the final result, and the accuracy of a test of this type is therefore definitely less than that of the transfer test.

The transfer instruments usually used at the National Bureau of Standards are of the electrodynamic type. The voltmeter in use at the present time has been described in a previous publication. ${ }^{3}$ The present paper describes the wattmeter now being used. Although designed primarily as a wattmeter, this instrument may also be used as an ammeter if it is connected to measure the power consumed in an external shunt.

\section{DESIGN AND CONSTRUCTION}

\section{CRITERIA OF DESIGN}

A transfer instrument to be satisfactory for the type of testing work done at the National Bureau of Standards should possess, so far as possible, the following desirable characteristics:

(1) The frame of the instrument should be made from a nonmagnetic, nonconducting material. This material should lend itself to a sufficiently sturdy and permanent construction to avoid future difficulties resulting from warping of the instrument frame and consequent sticking of the moving system.

(2) The zero drift of the instrument on steady deflection should be as small as possible.

(3) The sensitivity of the instrument should be such that a change of 0.01 percent of the total deflection can be detected readily and with certainty on all ranges.

(4) The ac-dc differences of the instrument, that is, the differences between the indications of the instrument on alternating current and the average of its indications on reversed direct current, should be negligible for power frequencies and as low as possible for somewhat higher frequencies.

(5) The instrument should be astatic in construction.

(6) The damping of the moving system should be slightly less than critical.

(7) The response time ${ }^{4}$ of the instrument should be reasonably short, preferably not greater than 10 sec.

(8) The two moving coils, the reflecting mirror, and the damping vane should be rigidly interconnected in order to avoid forced vibrations of these parts with respect to each other.

(9) The indication of the instrument should be read easily and with a minimum of eyestrain.

(10) The moving system should be suitable for use on voltages up to $300 \mathrm{v}$, and the fixed-coil system should have a primary current range of $5 \mathrm{amp}$ and such additional ranges as can be obtained without undue difficulty.

\footnotetext{
${ }^{3}$ F. K. Harris, A suppressed-zero electrodynamic voltmeter, BS J. Research 3, 445 (1929) RP105.

4 The response time of an instrument is the time required for the pointer of the instrument to come to apparent rest after a change in the value of the measured quantity.
} 
These desirable characteristics are listed in their approximate order of relative importance as determined largely by the previous experience of members of the staff in the construction and use of similar instruments. It was proposed to incorporate these characteristics in the construction of the new instrument so far as was compatible with their sometimes conflicting requirements.

\section{GENERAL FEATURES OF DESIGN}

Since pivot friction could seriously limit the sensitivity attainable, pivots are not used but the moving system is suspended from top and bottom on two phosphor-bronze ribbons. The deflection of the instrument is read on a ground-glass scale by means of a beam of light reflected from a small mirror attached to the moving system. The distance from mirror to scale is $2 \mathrm{~m}$, giving the instrument an effective scale length, at full-scale deflection, of about $4 \mathrm{~m}$. The instrument is made astatic by using two sets of moving and fixed coils, one placed slightly above the other, the direction of winding lof one set of coils being reversed with respect to the direction of winding of the other. Air damping is provided by mounting a rectangular damping vane on the moving system and having it rotate within a fixed damping box. In order to obtain the most nearly linear relation between deflection and power being measured, the moving coils are held near the position of zero mutual inductance between the fixed and moving coils when the moving coils are deflected to their full-scale position. This is accomplished by resetting the series resistor in the voltage circuit for each nominal value of watts being measured. The mechanical zero of the instrument need not be disturbed, and the deflection of the moving system is thus approximately the same, regardless of the nominal value of watts being measured. The result is to minimize the zero shift, on steady deflections, resulting from the inelastic yielding of the spring and suspensions. This means, in turn, that it is permissible to make less frequent calibrations of the instrument on direct current when it is being used as a standard a-c wattmeter or ammeter.

\section{DETAILS OF DESIGN AND CONSTRUCTION}

(a) SUPPORTING FRAMEWORK

One of the chief婯difficulties encountered with previous transfer instruments has been warping of the supporting framework, which resulted in sticking of the moving system. The difficulty of locating and removing the causes of this misalinement, and the consequent sticking, led to the conclusion that the framework of the new instrument should be made of materials less subject to warping than wood and which preferably allowed some degree of vision within the instrument. Since all metallic materials are out of the question because of eddy-current or magnetic errors, the field of choice was very limited. After some discussion it was decided to use glass for the supporting framework, since it is nonwarping and nonmagnetic, permits a certain amount of vision within the instrument, can be obtained readily in slabs of almost any reasonable size, and can be readily worked if care is used.

The fixed coils and the damping box are each split into two halves in a vertical plane, each half being mounted in a rectangular glass panel. 
These glass panels are hinged to each other, one being stationary and the other opening and closing like a door. In the closed position the corresponding halves of the fixed coils and the two halves of the damping box fit snugly together to form two complete fixed coils and one damping box.

The difficulty of attaching hinges directly to the glass forced the use of supporting frames of mahogany for the two glass panels. The hinges are attached to these frames. These frames also allow the lack of squareness of the corners of the glass panels to be corrected for and concealed. The use of any wood at all is an undoubted disadvantage. However, half of each fixed coil, half of the damping box, and the entire moving system are supported entirely by the stationary glass panel. The other half of the fixed-coil system and the other half of the damping box are supported by the second glass panel, which is attached to the first panel by the hinges and the mahogany frame. Any warping of the wooden frames can result only in a displacement of the entire second panel with respect to the first panel. The possibility of warping was reduced to a minimum by carefully varnishing the mahogany inside and out.

In order to provide an immediate and visible check on any gross misalinement of the two glass panels with respect to each other, two groups of fiducial marks were etched on the panels. Those groups were placed at widely separated intervals on the panels. Each group consists of a large cross etched on the rear surface of the rear panel, a smaller cross on the rear surface of the front panel, and a still smaller cross on the front surface of the front panel. With the instrument as originally assembled, the panels properly alined and the moving system free from sticking, the three crosses constituting each group lie accurately on a straight line perpendicular to the face of the panels. They may therefore be lined up by eye so as to fall one upon the other. Any subsequent displacement of one of the panels with respect to the other will be evident as a displacement of these fiducial marks from a straight line. It will be possible to bring the panels back into their original alinement by inserting suitable shims between the glass panels and the wooden frames.

The glass panels were made of plate glass of rectangular shape, $1 \mathrm{in}$. thich and $8 \mathrm{in}$. wide by 44 in. long. The only machine work required was to cut the glass to size and drill holes through it for mounting the wattmeter parts. Round holes are readily put through glass by using a tubular tool in a drill press with carborundum and water as a grinding compound. Holes of other shapes can be made by drilling a series of small round holes around the outline desired and then smoothing down the edges with a flat brass tool worked by hand with carborundum. The only prerequisite in working this glass was found to be patience. The location and size of the holes drilled in the glass panels are shown on the assembly drawing of the wattmeter in figure 1 .

The fixed coils were mounted on the glass panels by first embedding them in bakelite holders which could be inserted into round holes in the glass panels. An attempt was made to mold the fixed coils into the Bakelite holders under heat and pressure by constructing a die which was used in a vulcanizing press. The heat and pressure of the press destroyed the insulation of the coils and the attempt had to be abandoned. The die was remade for molding cylindrically shaped 
coil holders closed at one end. The fixed coils were cemented into these holders with sealing wax. Coils thus made have been in service 5 years now and still appear to be very solid. The coils in their holders were fixed in the glass panels with fiber shims pressed and cemented in place with a cellulose-acetate cement. The Bakelite holders were slightly smaller than the holes, and the holes in the glass were slightly conical to permit this construction. In constructing another instrument it might be desirable to make the holes even more conical deliberately for this purpose.

The damping box was made of molded Bakelite. It was molded in two pieces, the same die being used for each piece. Each half of the damping box fits into an opening in the bottom of each glass panel, as is shown in figure 1, and was fixed firmly in position by small wedges cemented in place. An opening was also made in the upper half of the movable glass panel to allow the free passage of a beam of light to and from the mirror attached to the moving system. The trim surrounding this opening was also made of moldedikBakelite. A thin piece of cover glass, cemented on the rear surface of this piece of trim, allows the passage of light but protects the interior of the instrument from the stray air currents of the room.

\section{(b) FIXED COILS}

To obtain a high sensitivity for the completed instrument, the flux density at the moving coils, due to current flowing through the fixed coils, should be as great as possible. This would require a maximum number of ampere turns concentrated in a small space as a fixed coil. A limit as to the size of wire for the fixed coils, and thus to the allowable current flow through the instrument, is set by the introduction of eddy currents and skin effects in the larger sizes of wire. Number 16 copper wire, for which eddy currents and skin effects are negligible at power frequencies, was used in winding the fixed coils. A limit to the number of turns in the fixed coils is set by the introduction of capacitance currents. To keep these capacitance currents low, and to obtain some flexibility in current rating, four No. 16 silk-enamel copper wires were formed into a cable. These cables were then wound into tight coils (32 turns of cable per coil) on a coil-winding machine. A piece of fiber tubing, turned to the correct inside diameter, was slipped over the coil after completion of the winding; the coil and tubing were lashed together and repeatedly soaked in insulating varnish and baked. After the final baking, the fiber tubing was stripped from the coil and the coil mounted in the molded coil holders previously mentioned, with the aid of sealing wax. These coil holders were in turn mounted in the glass panels as previously indicated (see fig. 1).

Two different types of fixed coil were made (see fig. 2 for the shape and dimensions of each style of coil). Tests on the completed wattmeter showed that style $B$ gave the better performance, and coils of this style are permanently mounted on the glass panels.

Four of these coils are required for the completed instrument, two mounted in each glass panel in such a manner that with the panels closed and face to face two complete fixed coils are formed, one above the other. Sufficient space is left to allow a moving coil to be suspended in the center of each of the two fixed coils so formed. The cables of the four individual coils were connected in series in such a manner that the flux of the upper coil is in the direction opposite 


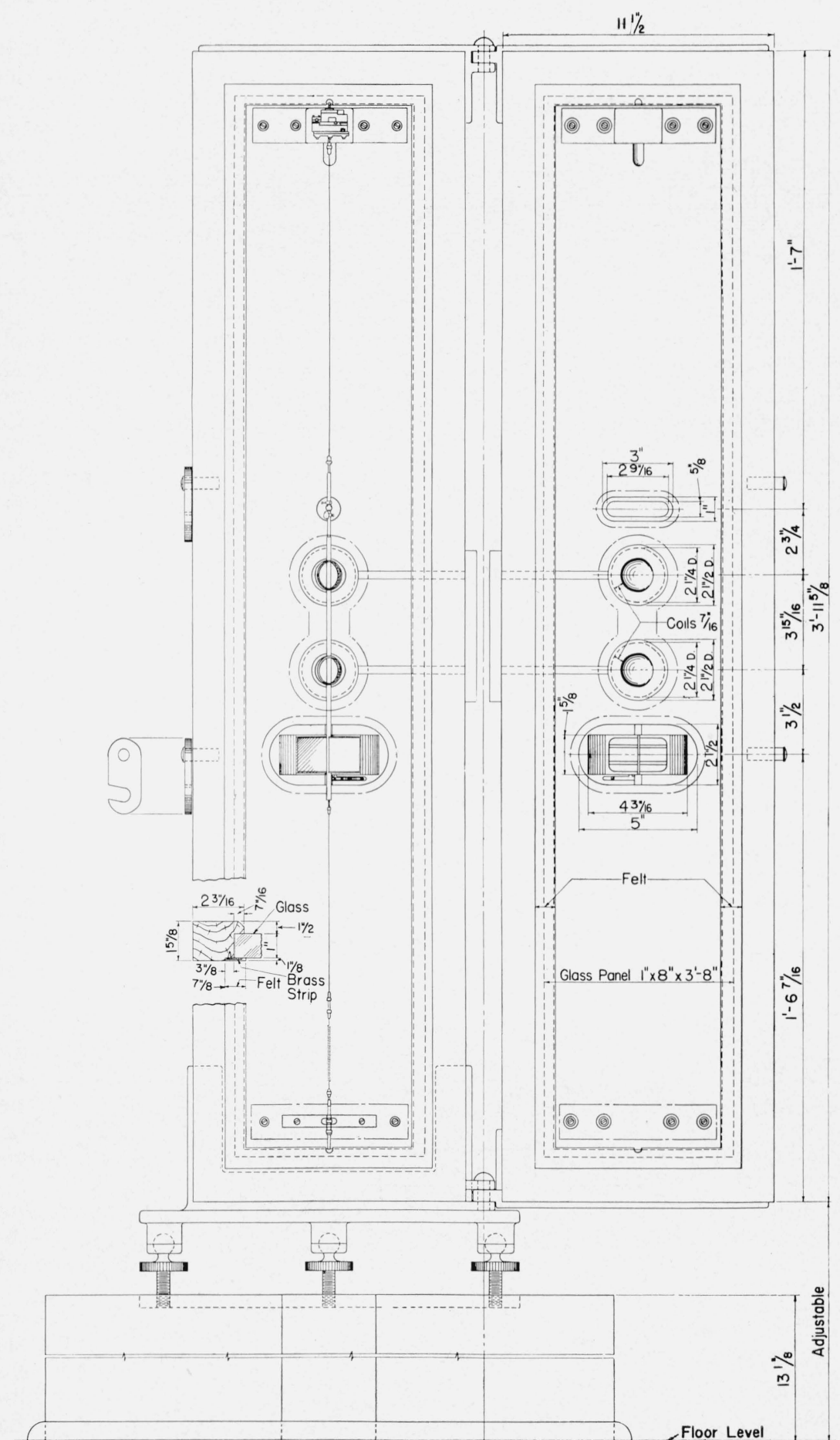

FIGURE 1.-Drawing of the complete wattmeter, with front panel open. 


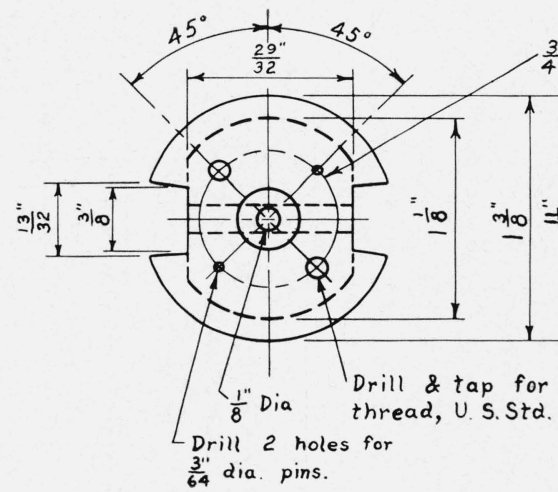
dia. for centers of holes
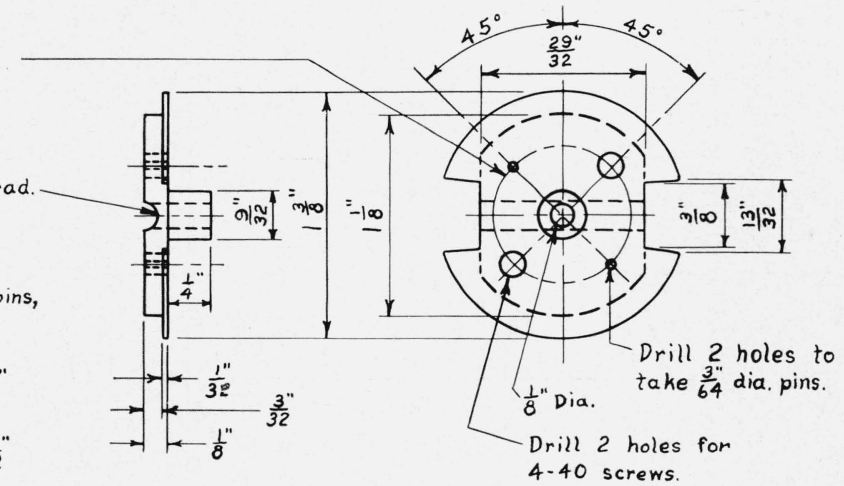

FIGURE 4.-The dimensions of the forms used for winding style B moving coils, which were permanently mounted in the completed instrument. Forms for style $A$ coils were similar except that the outside diameter of the winding channel was $11 / 16$ inch. 
to the flux of the lower coil, thus giving astatic construction. The two ends of the fixed-coil cable were brought out to a terminal board located on the wall near the wattmeter. The terminal board is arranged so that the four coils formed by the four wires in the fixed coil cable can be connected in series, series-parallel, or parallel.

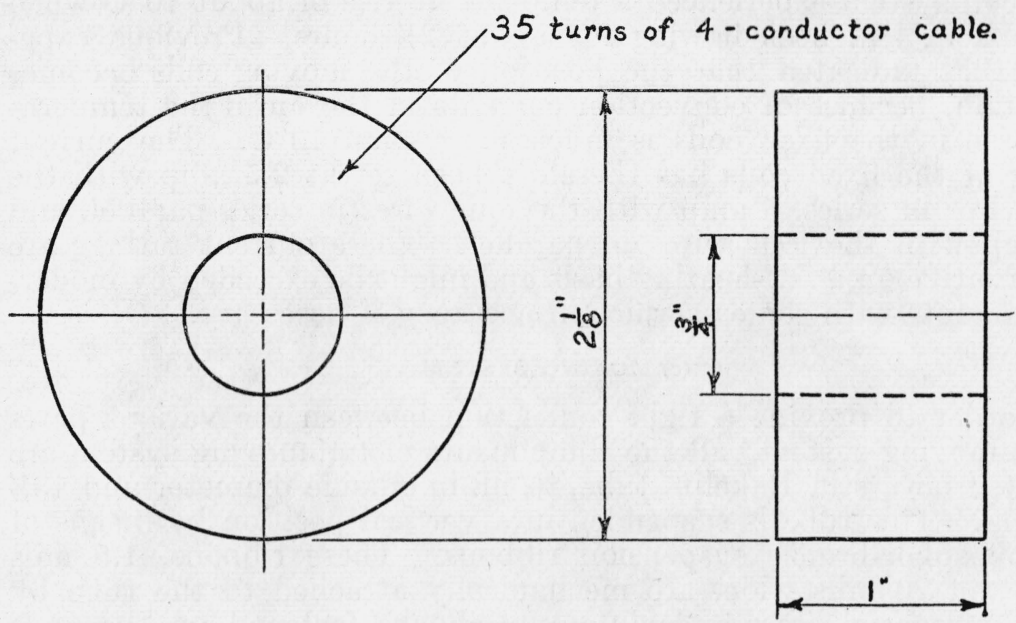

Style A

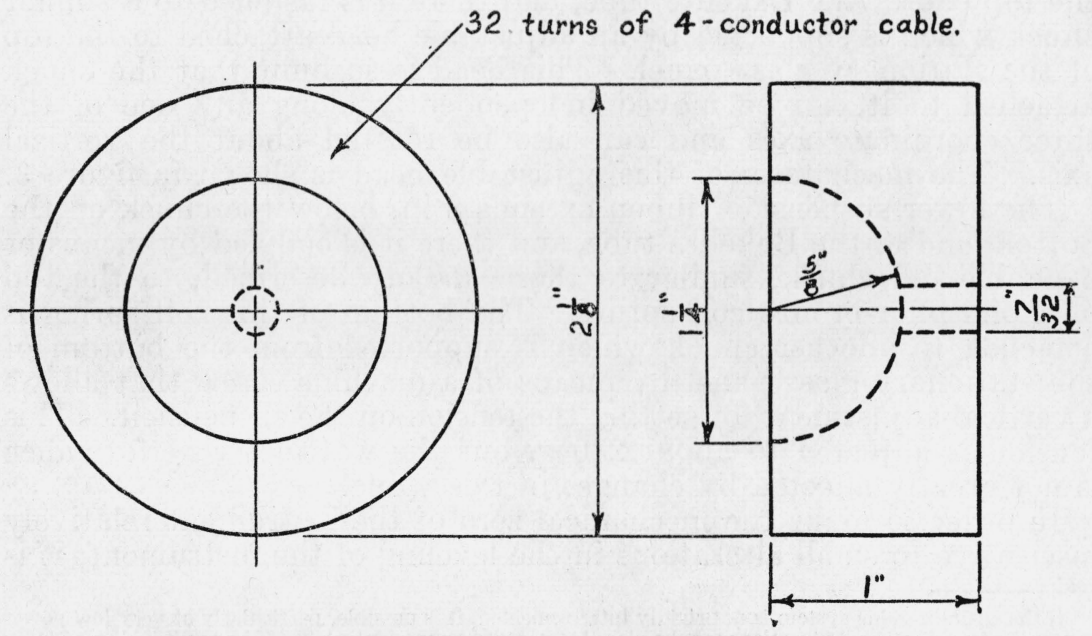

Style B

FIgURE 2.- The dimensions of the two styles of fixed coils. 
The current rating of the instrument is limited by the heating of the fixed coils. Each wire of the fixed-coil cable has a resistance of $0.25 \mathrm{ohm}$. Experimental heating runs were made with the fixed coils mounted in their working positions and with 2.5 amperes flowing in each wire of the fixed-coil cable. Under these conditions the fixed-coil system experienced a temperature rise of about $10^{\circ} \mathrm{C}$ when the current had been flowing for about $2 \frac{1}{2}$ hours. Previous experience has indicated that the position of the moving coils becomes uncertain, because of convection currents in the air, if the temperature rise in the fixed coils is much more than $10^{\circ} \mathrm{C}$. The current rating of the fixed coils has therefore been set at $2.5 \mathrm{amp}$ with the four wires in series, $5 \mathrm{amp}$ with the four wires in series-parallel, and $10 \mathrm{amp}$ with the four wires in parallel. These current ratings are conservative on a self-heating basis and might be exceeded by moderate amounts with some sacrifice in accuracy if necessary.

\section{(c) MOVING SYSTEM}

In order to provide a rigid connection between the various parts of the moving system, ${ }^{5}$ all the components of the moving system are mounted on a stiff Bakelite tube, $3 / 16$ in. in outside diameter and $131 / 2$ in. long: This tube is suspended in a vertical position by means of two phosphor-bronze suspension ribbons. These ribbons, $1.5 \mathrm{mils}$ thick and 20 mils wide, are mechanically attached to the tube by means of special brass and aluminum chucks fastened on the ends of the tube. The shank of each chuck is so milled as to allow the suspensions to come through under the shell. Thus the moving coil can be soldered directly to the end of the ribbon to form a definite electric contact, and the chuck jaws make a definite mechanical connection on a portion of the suspension which has not been softened by heating with a soldering iron. This construction minimizes zero shift and the failure of soldered joints in the moving system.

The upper suspension ribbon extends 12 in. above the chuck on the top end of the Bakelite tube, and there it is fastened to a similar chuck which is supported by an adjustable head attached to the top of the stationary glass panel. This head is so built that the chuck attached to it can be moved independently along any one of the three coordinate axes and can also be rotated about the vertical axis. The mechanism of this adjustable head is shown in figure 3.

The lower suspension ribbon extends 8 in. below the chuck on the bottom end of the Bakelite tube, and there it is coupled by means of a double-end chuck, similar to those already described, to the top of a phosphor-bronze coil spring. The bottom of this coil spring is attached to another chuck which is supported from the bottom of the stationary glass panel by means of a machine screw that allows a vertical adjustment for setting the tension on the suspension. This tension is adjusted to about $230 \mathrm{~g}$, but the wattmeter performance is not greatly affected by changes in this value.

In order to make the mechanical zero of the instrument relatively insensitive to small alterations in the leveling of the instrument, it is

5 If the entire moving system is not rigidly interconnected, it is possible, particularly at very low power factors, for forced internal vibrations to take place between its component parts. The result is a broadening of the reflected spot of light. Because of the varying scale law of the instrument, particularly if the moving coils are not at the position of zero mutual, the true position of the spot of light will not correspond to the midpoint of this broadened band of light. The apparent indication of the instrument will therefore be in error. 
desirable to have the center of mass of the moving system coincide with the line of suspension of the moving system. Weights for balancing the moving system are therefore attached to the Bakelite support rod by the use of a brass collar with three small threaded rods (120 degrees apart) projecting from the collar. The balancing weights consist of small thumb nuts fitting these threaded rods.

Two sizes of moving coils were made originally, one with a 13/16-in. outside diameter to fit style $A$ fixed coils, and the other with a $13 / 16$ in. outside diameter to fit style $B$ fixed coils. Because of the greater sensitivity of the wattmeter with this latter combination, as explained in section d, Preliminary Tests of Wattmeter, style $B$ fixed coils and

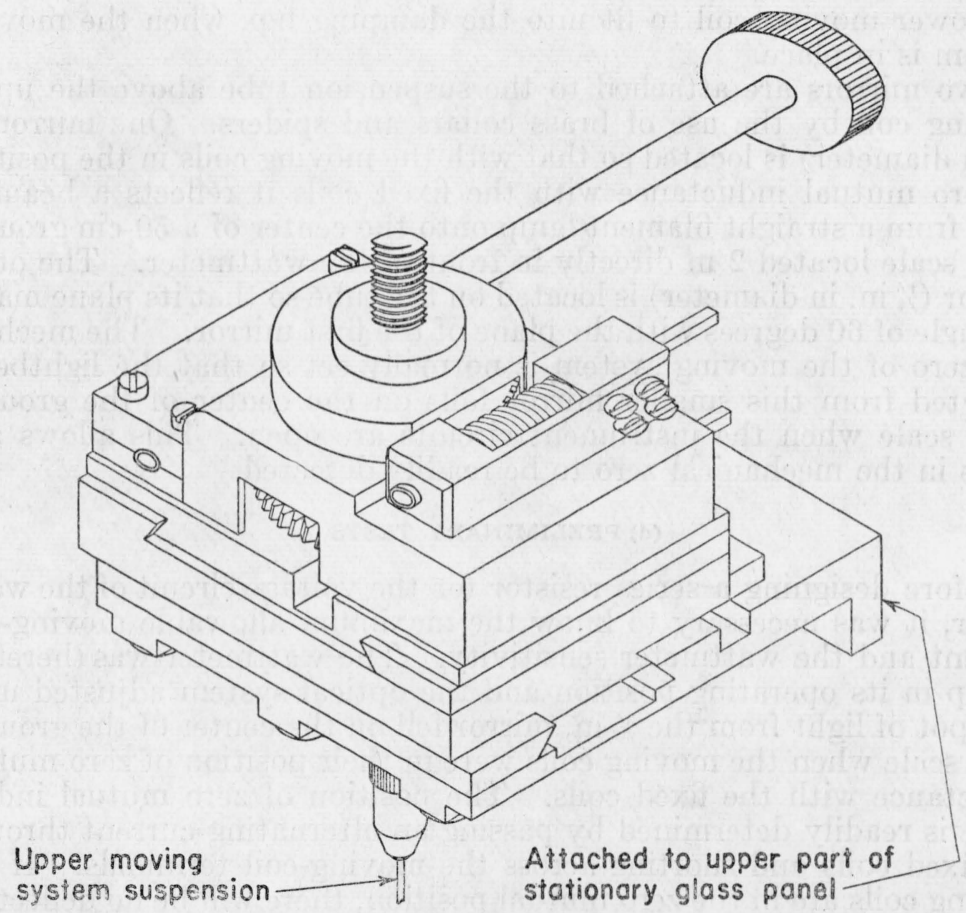

Figure 3.-Details of the movable head to which the upper end of the suspension is attached.

the larger moving coils were chosen for permanent mounting in the wattmeter.

The details and dimensions of the brass forms used for winding these coils are given in figure 4. Each coil contains 100.5 turns of No. 32 silk-enamel copper wire. After each layer of a coil was wound (about 19 turns), a coat of thin shellac was applied and allowed to dry. This served to hold the completed coil together after removing the form. The completed coil was then dipped in thin insulating varnish and baked at about $120^{\circ} \mathrm{C}$ for 24 hours. This procedure was repeated four times to form a tough protective coating over the coil and to give it rigidity. The coils were mounted on the moving system by inserting the suspension tube through the two holes in the 
top and bottom of the coil. After the moving coils were located on the tube so as to fit into the hollow centers of the fixed coils and the two moving coils were twisted into the same plane, they were lashed to the tube with silk thread and shellac was applied to hold them rigidly to the tube. The two moving coils were connected in series in such a manner that the direction of winding on the upper coil is reversed with respect to the direction of winding on the lower coil. The two remaining free ends of the coils were then soldered to the upper and lower suspensions.

The damping vane, $1 \frac{1}{2} \mathrm{in}$. high by $4 \mathrm{in}$. wide, is made of $10-\mathrm{mil}$ sheet aluminum with the edges rolled for stiffness. This damping vane is riveted to the suspension tube at the proper distance below the lower moving coil to fit into the damping box when the moving system is in place.

Two mirrors are attached to the suspension tube above the upper moving coil by the use of brass collars and spiders. One mirror $(3 / 8$ in. in diameter) is located so that with the moving coils in the position of zero mutual inductance with the fixed coils it reflects a beam of light from a straight filament lamp onto the center of a $50-\mathrm{cm}$ groundglass scale located $2 \mathrm{~m}$ directly in front of the wattmeter. The other mirror ( $1 / 4$ in. in diameter) is located on the tube so that its plane makes an angle of 60 degrees with the plane of the first mirror. The mechanical zero of the moving system is normally set so that the lightbeam reflected from this smaller mirror falls on the center of the groundglass scale when the instrument circuits are open. This allows any shifts in the mechanical zero to be readily detected.

\section{(d) PRELIMINARY TESTS}

Before designing a series resistor for the voltage circuit of the wattmeter, it was necessary to know the maximum allowable moving-coil current and the wattmeter sensitivity. The wattmeter was therefore set up in its operating position and the optical system adjusted until the spot of light from the $3 / 8$-in. mirror fell on the center of the groundglass scale when the moving coils were in their position of zero mutual inductance with the fixed coils. The position of zero mutual inductance is readily determined by passing an alternating current through the fixed coils and shorting across the moving-coil terminals. If the moving coils are in the zero mutual position, there will be no deflection of the moving system. If they are not at the position of zero mutual, there will be an emf induced in them and a current will flow when their terminals are shorted, causing a deflection towards the position of zero mutual. This test can be made as sensitive as desired by increasing the frequency of the current in the fixed coils.

A preliminary value of the sensitivity of the wattmeter with the moving coils in the position of zero mutual was determined by passing rated direct current (2.5 amp per wire) through the fixed coils and measuring the direct current through the moving coils necessary to obtain a deflection of about $10 \mathrm{~cm}$ with a scale distance of $2 \mathrm{~m}$. The sensitivity with style $A$ fixed coils and the smaller moving coils was found to be $34 \mathrm{~cm} / \mathrm{ma}$ in the moving coil. The sensitivity for style $B$ fixed coils and the larger moving coils was found to be $125 \mathrm{~cm} / \mathrm{ma}$ in the moving coils. These latter were therefore permanently mounted in the instrument. This latter sensitivity might alternatively be 
expressed as 2.4 milliradians per ampere turn in the fixed system per ampere turn in the moving system.

The maximum allowable current through the moving coils is limited by the heating due to this current. A heating test was made with 2.5 amp through the fixed coils (all connected in series) and $0.1 \mathrm{amp}$ through the moving coils. Under these conditions the moving coils showed a temperature rise of $9.5^{\circ} \mathrm{C}$ at the end of $2 \frac{1}{2}$ hours. A current of $0.1 \mathrm{amp}$ is therefore considered a safe value for the moving system. Higher current values might be used, but their use is not anticipated at this time.

\section{(e) SERIES RESISTOR}

The resistors to be used with the moving coils of this instrument to form the voltage circuit were designed to be adjustable over such a range that by means of this adjustment the instrument deflection could be brought to the same value for any nominal value of watts to be measured. A total deflection of $400 \mathrm{~cm}$ was chosen, thus allowing a change in deflection of 0.01 percent $(0.4 \mathrm{~mm})$ to be observed easily. With a sensitivity of $125 \mathrm{~cm} / \mathrm{ma}$ in the moving coils for rated current in the fixed coils, a plain series resistor must have a maximum resistance of $337 \mathrm{ohms}$ per volt; that is, about $100,000 \mathrm{ohms}$ for the maximum voltage range of $300 \mathrm{v}$. The minimum fixed-coil current (with fixed coils connected in series) at which the wattmeter is expected to be used is $0.25 \mathrm{amp}$ (25-percent load on the 1-amp range of a watthour meter). This requires a maximum moving-coil current of $0.03 \mathrm{amp}$ to obtain a deflection of $400 \mathrm{~cm}$. It was decided to design the resistor for a maximum current of $0.06 \mathrm{amp}$ and to provide a circuit arrangement which would give a moving-coil current equivalent to that which would be obtained if a plain series resistor were used with a maximum resistance of $200,000 \mathrm{ohms}$.

The arrangement of resistors and their electric connections designed to meet these requirements is shown in figure 5. A fixed resistance of $985 \mathrm{ohms}$ is connected in series with the wattmeter moving coil, and a capacitance of 0.001 microfarad is connected across a $937-\mathrm{ohm}$ section of this resistor to compensate for the inductance of the moving coils. The "series resistance" consists of nine $1-\mathrm{ohm}$, nine 10-ohm, nine $100-\mathrm{ohm}$, and nine $1,000-\mathrm{ohm}$ coils connected to four 10-step selector switches so that any resistance from zero to $9,999 \mathrm{ohms}$, in 1-ohm steps, may be connected. The "shunt resistance" is connected in parallel with the moving coil and the $985-\mathrm{ohm}$ resistor. The value of this shunt resistance may be set at $\infty, 1,000,400,200,100$, or $50 \mathrm{ohms}$ by means of a 6 -step selector switch. The purpose of the shunt resistance is to decrease the current through the moving coil, which, as regards voltage sensitivity, is the equivalent of increasing the series resistance. This allows an effective series resistance of $200,000 \mathrm{ohms}$ to be attained while the actual value of the series resistor is kept below 10,000 ohms. The coils used in the shunt resistance (1,000 ohms and lower) are much cheaper and less apt to give trouble than the $10,000-0 h m$ coils that would be needed in the series resistance if a shunt resistance were not used. In addition the capacitance errors of the $1,000-\mathrm{ohm}$ coils will be much less than the capacitance errors of $10,000-\mathrm{ohm}$ coils.

A 1- $\mu$ f paper capacitor can be connected across the 985 -ohm resistance which is in series with the wattmeter moving coils by means of the push-button switch marked "P. F. test." When this capacitor is 
connected, the current through the moving coils is made to lead in phase with respect to the supply voltage. Thus, if the current supplied to the wattmeter fixed coils is lagging in phase with respect to the supply voltage, pushing the "P. F. test" button will cause the

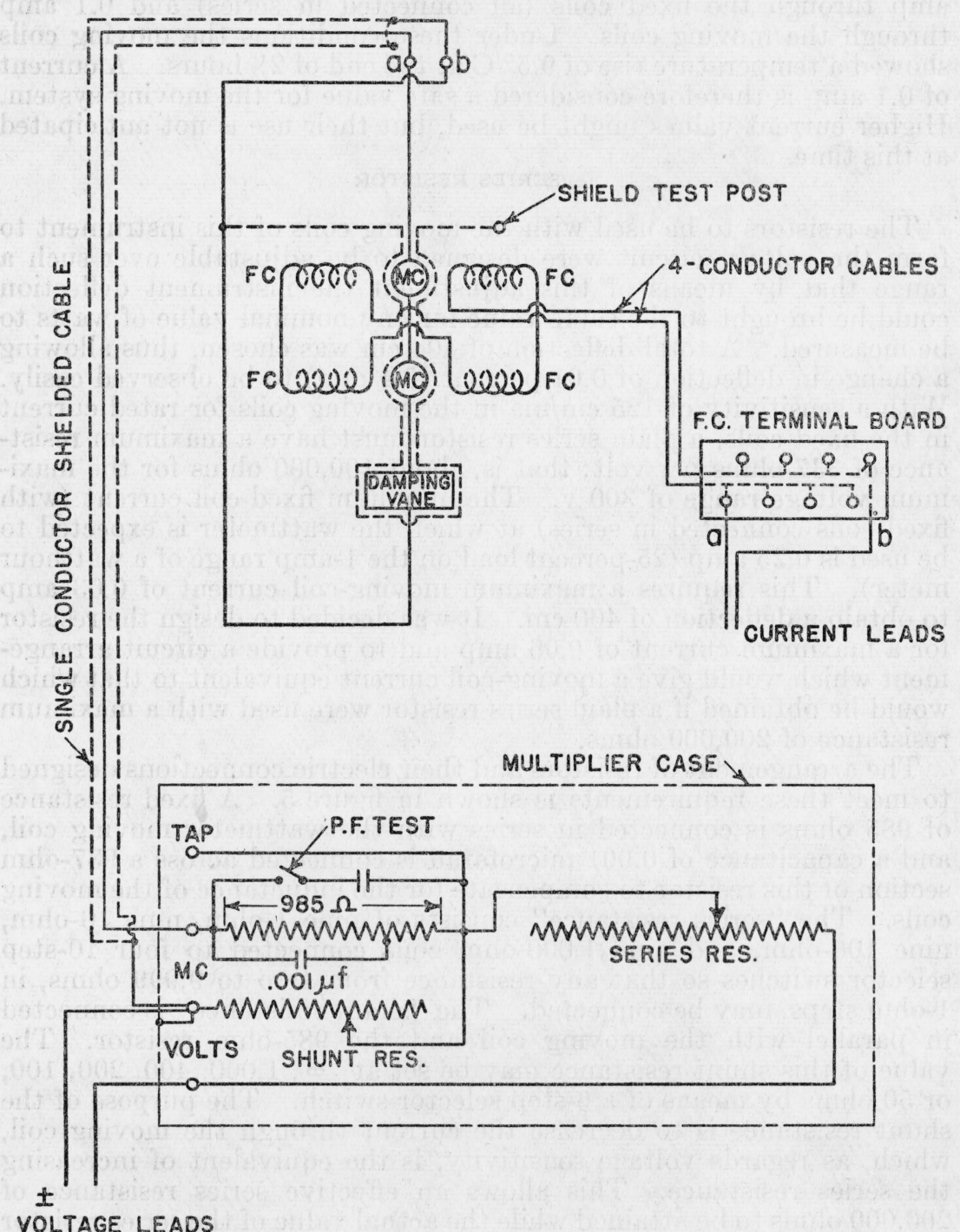

FIGURE 5.-Schematic diagram of the wattmeter and multiplier connected for measuring power, showing shield circuits.

wattmeter deflection to decrease; if the current is leading, pushing this button will cause the wattmeter deflection to increase. Because of the slight decrease in impedance of the wattmeter voltage circuit when the 1- $\mu$ f capacitor is connected, this "leading" or "lagging" test is ambiguous when the power factor is greater than 0.9 . 
The resistance units used in this multiplier are all of commercial construction, except an 85-ohm. section of the $985-\mathrm{ohm}$ resistor connected in series with the moving coils. This $85-0 h m$ resistor was made in this laboratory. It is of bifilar construction in two sections, allowing a tap to be brought out at the proper point for connecting the 0.001- $\mu$ f compensating capacitor. The 1- and 10-ohm units are also of bifilar construction. All other units were of a special "woven" construction which reduces the time constant to the lowest value attainable for precision resistors. They are mounted on porcelain tubes $7 / 8$ in. in diameter and $3 \frac{1}{2}$ in. long and then dipped in "Ceresin" wax. The units are all made of manganin wire, and with a current of $60 \mathrm{ma}$ their maximum temperature rise was specified to be less than $25^{\circ} \mathrm{C}$. In order to obtain this current rating, the $1,000-\mathrm{ohm}$ units are each made up of four 4,000-ohm windings mounted on separate spools and connected in parallel.

All the component parts of the multiplier are mounted on a hardrubber panel $1 / 2$ by $11 \frac{1}{2}$ by $201 / 2$ in. This hard-rubber subpanel is concealed from exposure to light by an aluminum panel $1 / 8$-in. thick placed $1 / 2$ in. in front of it and attached to it by brass screws and hardrubber spacers. The shafts of the selector switches and the binding posts protrude through the aluminum panel without touching it. These two panels are screwed to an aluminum base $1 / 4$ by 5 by $201 / 2$ in. A one-piece brass cover is bent up to fit over the top, back, and two sides. The completed multiplier box is fastened in an upright position at the back of the observer's table, the ground-glass scale being located 5 in. in front and 3 in. above it.

\section{(f) SHIELDING}

In order to minimize the effect of capacitance currents between the moving and fixed coils and to prevent the accumulation of electrostatic charges near the moving coils or damping vane, it is usual to provide a conducting screen or shield between the fixed and moving parts. In the present instrument conducting paint was used in making this shield. Four $1 / 8$-in. stripes are painted along the axes of great circles on the inside of the hemispherical depression in each fixed coil so that they cross each other at the deepest point in the depression. The inside surface of each half of the damping box is coated with this paint, the glass windows being left clear except for two $1 / 8$-in. stripes painted across them. All sections of the shield are connected in series by a $1 / 8$-in. stripe of conducting paint, the connection from the stationary glass panel to the hinged panel being made by a spring contact between the two halves of the damping box. One end of this series circuit is connected to the moving-coil lead going to the bottom suspension (the damping vane is soldered to the lead from this suspension to the lower moving coil). The other end of the series circuit is brought out to a binding post on the mahogany frame of the hinged panel. A measurement of the resistance between this binding post and a moving-coil terminal thus serves as a check on the continuity of the shield. This resistance as measured by a $1 \frac{11}{2}-\mathrm{v}$ ohmmeter is about $50,000 \mathrm{ohms}$.

A schematic diagram of the location and interconnection of the shields used in the instrument is shown in figure 5. The wattmeter moving coil is connected to the multiplier by a single-conductor 
shielded lead with rubber insulation over the shield (the capacitance between conductor and shield being $710 \mu \mu \mathrm{f}$ ). At the wattmeter end, the shield of this lead is connected through a binding post to the lower moving-coil suspension, which is also tied to the wattmeter shield. The central wire of this lead is connected through a binding post to the upper moving-coil suspension. At the multiplier end, the shield of this lead is connected to the lower moving-coil "MC" binding post (the " \pm " supply voltage lead to which the electrostatic tie between current and voltage circuits is attached is also connected to this binding post). The central wire of the shielded lead is connected to the upper moving-coil binding post. The multiplier metal case is tied to the lower moving-coil binding post and thus acts as a shield for the multiplier.

(g) WATTMETER CONSTANTS

(1) Fixed coils.

1. Connected in series (2.5 amp), resistance $0.848 \mathrm{ohm}$, self inductance $1,300 \mu \mathrm{h}$.

2. Connected in series-parallel (5 amp), resistance $0.212 \mathrm{ohm}$, self inductance $304 \mu \mathrm{h}$.

3 . Connected in parallel $(10 \mathrm{amp})$, resistance $0.053 \mathrm{ohm}$, self inductance $72 \mu \mathrm{h}$.

4. Mutual inductance between any two of the four fixed coils, $85 \mu \mathrm{h}$.

5. Average capacitance between two of the four fixed coils, $0.003 \mu \mathrm{f}$.

6. Capacitance from fixed coils to shield, $200 \mu \mu f$.

7. Maximum heating of fixed coils with rated current, $10^{\circ} \mathrm{C}$.

8. Flux density at moving coils with rated current flowing in fixed coils, 110 gauss.

(2) Moving system.

1. Resistance of single moving coil, $5.3 \mathrm{ohms}$.

2. Resistance of entire moving system (between terminals on back of wattmeter), $15.30 \mathrm{ohms}$.

3 . Self inductance of moving system, $830 \mu \mathrm{h}$.

4. Mutual inductance between fixed coils (connected in seriesparallel) and moving coils at position of mechanical zero (58 degrees from position of zero mutual inductance between fixed and moving coils), $135 \mu \mathrm{h}$.

5. Capacitance between moving system and shield, $52 \mu \mu \mathrm{f}$.

6. Capacitance between moving system and fixed coils (with shield at same potential as moving system), $9 \mu \mu \mathrm{f}$.

7. Maximum heating of moving coils with $0.1 \mathrm{amp}$ flowing through them and rated current through fixed coils, $10^{\circ} \mathrm{C}$.

8. Total weight of moving system, $18 \mathrm{~g}$.

9. Period of moving system, 8 sec.

10. Torque required to deflect moving system from mechanical zero to full scale (position of zero mutual), 30 dyne $\mathrm{cm}$.

11. Stiffness of suspension, 0.5 dyne $\mathrm{cm} / \mathrm{deg}$.

12. Natural frequency of internal resonance; with direct current on fixed coils and alternating current on moving coils maximum vibration occurs at $80 \mathrm{c} / \mathrm{s}$. 


\section{PERFORMANCE TESTS}

\section{DIRECT-CURRENT ACCURACY}

Before the ac-dc errors were determined, the accuracy of the instrument assuming no ac-dc errors, that is d-c accuracy, was investigated. The factors effecting the d-c accuracy are (1) drift of deflection with time for a constant value of power, (2) variation of wattmeter sensitivity for small changes in deflection, and (3) imperfection of astatic construction.

With a constant value of current in the fixed coils and a constant voltage across the moving-coil circuit, the deflection of the wattmeter was noted during a period of 2 hours. The drift in deflection was found to be very nearly a linear function of time and equal to 0.1 $\mathrm{mm} / \mathrm{min}$. In ac-de transfer tests the effect of this drift is cancelled in the average a-c and d-c readings by the sequence in which the readings are taken. When the instrument is used as a standard wattmeter, it is calibrated on direct current before and after the a-c readings are taken so that here also the effects of drift tend to cancel. Even if the drift were not cancelled by the sequence of taking readings, the maximum error caused by it would be only 0.025 percent in 10 minutes.

In an ac-de transfer test of a wattmeter that is neither magnetically shielded nor of astatic construction, the reading of the standard instrument may be several percent different for one direction of current and voltage than for the reversed direction; also, the a-c reading may be slightly different from the d-c readings. Since the scale of the standard instrument is uniform, if its sensitivity is different for the various readings of the standard instrument in one set of data, an error will be introduced which may be as large as the percentage difference in sensitivity.

The sensitivity of the wattmeter can be derived from the following quantities:

$G=$ torque on moving system in dyne-centimeters per milliampere in the moving coils with rated current in the fixed coils.

$\alpha=$ angular deflection of moving system from the mechanical zero position as measured by the travel in centimeters of the working spot of light at a $2-\mathrm{m}$ radius from the mirror.

$U=$ restoring torque of suspension in dyne-centimeters per unit of angular deflection, $\alpha$.

$i=$ moving-coil current in milliamperes.

Since the summation of the torques on the moving system is zero, for any fixed position of the moving system

$$
i G-\alpha U=0 \text { or } \alpha=i \frac{G}{U},
$$

that is, the wattmeter sensitivity as deflection in centimeters per milliampere in the moving coils is $G$ divided by $U$. From Hooke's Law $U$ is constant but

$$
G=K \frac{d M}{d \alpha}
$$


where $M$ is the mutual inductance between the moving and fixed coils. Thus sensitivity is a function of the position of the moving coils with respect to the fixed coils but is independent of the mechanical zero or total deflection of the moving system.

The true value of sensitivity is obtained by measuring $\alpha$ for a given value of $i$ and dividing $\alpha$ by $i$. In the present wattmeter with a $50-\mathrm{cm}$ scale and a total normal deflection from mechanical zero position of $400 \mathrm{~cm}$, it is not feasible to obtain an accurate value of $\alpha$ at normal deflection. However, the changes in $\alpha$ over the range of the $50-\mathrm{cm}$ scale can be accurately measured, and if the total deflection is known to a fairly close approximation for one point on the scale, the changes in sensitivity on the scale can be accurately determined.

The values of relative sensitivity (which are absolute values within 0.3 percent and which show changes in sensitivity over the scale range within 0.01 percent) were obtained by holding rated current through the fixed coils and measuring the moving-coil currents required to deflect the moving system from the normal mechanical zero position (beam of light from small mirror on center of scale) to various positions of the working spot on the scale at 5 -cm intervals. Since the sensitivity is very nearly constant at the point of zero mutual inductance, a reference value of sensitivity at this point was computed from the values of $\alpha$ and $i$ at points $5 \mathrm{~cm}$ to the right and left of this point, that is,

$$
\alpha_{R}=\frac{G_{0}}{U} i_{R} \quad \alpha_{L}=\frac{G_{0}}{U} i_{L}
$$

from which

$$
\frac{G_{0}}{U}=\frac{\alpha_{R}-\alpha_{L}}{i_{R}-i_{L}}
$$

and the total deflection at the point of zero mutual inductance is

$$
\alpha_{0}=\frac{G_{0}}{U} i_{0}
$$

The total deffection at any other point on the scale was found by adding the difference between the scale reading at this point and the scale reading at the point of zero mutual to the total deflection at the point of zero mutual. This gave total relative deflections for various points on the scale which were as accurate as the scale could be read.

From these data the relative wattmeter sensitivity at any point on the scale was computed by dividing the total deflection at the point by the moving-coil current required to deflect the wattmeter to this point. The relative sensitivity this obtained is in deflection (in centimeters) per milliampere in the moving coils with rated current in the fixed coils. A plot of this sensitivity against scale reading is shown in figure 6 . This plot shows that there is a range of $10 \mathrm{~cm}$ near the point of zero mutual within which the sensitivity is constant to within 0.01 percent. Thus no corrections for wattmeter sensitivity are required for readings within this range. For readings outside this range corrections ${ }^{6}$ can be applied.

As seen from the curve of figure 6 , the point of zero mutual inductance between the fixed and moving coils (as indicated by the arrow)

\footnotetext{
${ }^{6}$ For a computation of these corrections see appendix I.
} 
does not exactly coincide with the point of maximum sensitivity. If the flux density due to the fixed coils were uniform throughout the volume occupied by the moving coils, maximum sensitivity, that is maximum $d M / d \alpha$, would come at the point where $M=0$. The con-

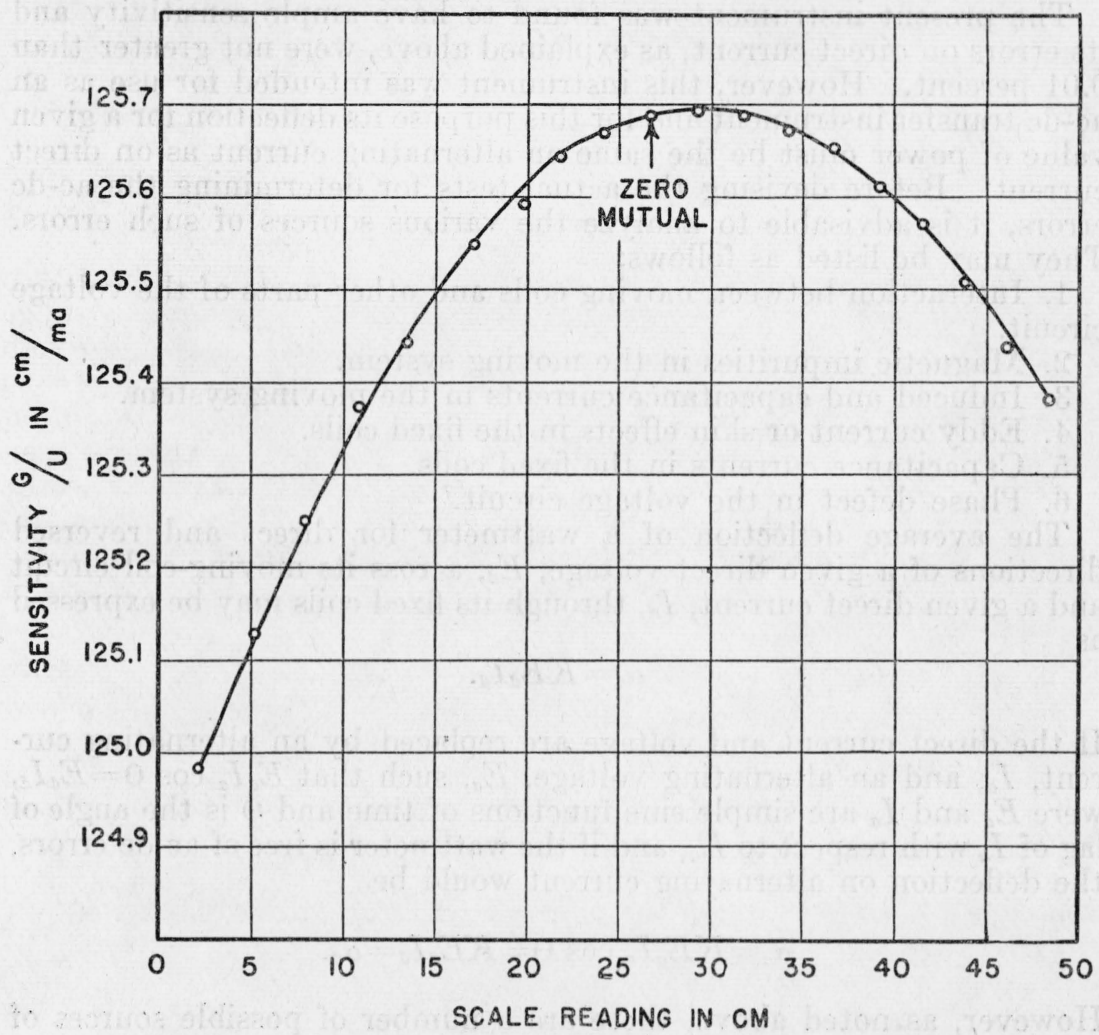

FiguRE 6.-Relative wattmeter sensitivity for various positions of working spot on the ground-glass scale in centimeters of deflections per milliampere in the moving coils with rated current in the fixed coils.

The absolute wattmeter sensitivity is equal to the relative sensitivity to within 0.3 percent.

clusion is that the flux density is not strictly uniform in the present instrument, and this is probably the case in most instruments of this type.

Imperfection of the astatic construction of the wattmeter results in a small deflection of the moving system with direct current through the moving coils only, because of interaction with the earth's magnetic field. This deflection was measured with $60 \mathrm{ma}$ (the maximum value to be used) through the moving coils for various positions of the moving system near the point of zero mutual inductance between the fixed and moving coils. These deflections as measured by the movement of the light beam on the ground-glass scale were found to be +0.07 $\mathrm{cm}$ for one direction of moving-coil current and $-0.07 \mathrm{~cm}$ for the other direction, and they were the same for all positions of the light beam on the scale within $\pm 15 \mathrm{~cm}$ of the point of zero mutual inductance. Thus in using the instrument for an ac-de transfer test, even though 
the two d-c readings are quite different, the small deflection due to lack of astaticism will be cancelled out in the average d-c reading.

\section{ANALYSIS OF AC-DC ERRORS}

The present instrument was found to have ample sensitivity and its errors on direct current, as explained above, were not greater than 0.01 percent. However, this instrument was intended for use as an ac-dc transfer instrument and for this purpose its deflection for a given value of power must be the same on alternating current as on direct current. Before devising the actual tests for determining the ac-dc errors, it is advisable to analyze the various sources of such errors. They may be listed as follows:

1. Interaction between moving coils and other parts of the voltage circuit.

2. Magnetic impurities in the moving system.

3 . Induced and capacitance currents in the moving system.

4. Eddy current or skin effects in the fixed coils.

5. Capacitance currents in the fixed coils.

6. Phase defect in the voltage circuit. ${ }^{7}$

The average deflection of a wattmeter for direct and reversed directions of a given direct voltage, $E_{d}$, across its moving-coil circuit and a given direct current, $I_{d}$, through its fixed coils may be expressed as

$$
\alpha_{d}=K E_{d} I_{d} \text {. }
$$

If the direct current and voltage are replaced by an alternating current, $I_{a}$, and an alternating voltage, $E_{a}$, such that $E_{a} I_{a} \cos \theta=E_{d} I_{d}$, were $E_{a}$ and $I_{a}$ are simple sine functions of time and $\theta$ is the angle of lag of $I_{a}$ with respect to $E_{a}$, and if the wattmeter is free of ac-dc errors, the deflection on alternating current would be

$$
\alpha_{a}=K E_{a} I_{a} \cos \theta=K E_{d} I_{d}=\alpha_{d} .
$$

However, as noted above, there are a number of possible sources of ac-dc errors and these errors enter into the above equation as (1) " $\Delta m$ ", a percentage change in magnitude of $E_{a} I_{a},(2)$ " $\tau_{w}$ ", in effect, a change in the angle $\theta$, and (3) " $\Delta \alpha$ ", a change in $\alpha_{a}$, which is a function of $I_{a}$ or $E_{a}$ but not of the product $E_{a} I_{a}$. When these three factors are put into the equation, the deflection on alternating current becomes

$$
\alpha^{\prime}{ }_{a}=K E_{a} I_{a}(1+\Delta m) \cos \left(\theta+\tau_{w}\right)+\Delta \alpha .
$$

and the difference between the average $d-c$ deflection and the a-c deflection is

$$
\alpha^{\prime}{ }_{a}-\alpha_{a}=\Delta m K E_{a} I_{a} \cos \theta-K E_{a} I_{a} \sin \theta \sin \tau_{w}+\Delta \alpha
$$

neglecting second-order terms.

The sources of ac-dc error listed above may now be separated into three groups according to their entrance in eq 1 as " $\Delta m$ ", " $\tau_{w}$ ", or

\footnotetext{
7 In uncompensated electrodynamic instruments the largest source of this phase defect is the inductance of the moving coils. In the present instrument this inductance is compensated by a capacitor connected across a section of the series resistor. Thus, this phase defect (difference in phase between the moving-coil current and the voltage across the voltage circuit) depends upon (1) the efficacy of the compensation, (2) the small residual inductance or capacitance in the series resistor, and (3) the small capacitance currents between various sections of the series resistor or from any of these sections to the multiplier case.
} 
" $\Delta \alpha$ ". Those entering as " $\Delta \alpha$ " will be present either with voltage only or with current only applied to the wattmeter, and by properly choosing the experimental conditions each one of these errors can be measured separately. The errors entering as " $\Delta m$ " may be measured as a group by determining the ac-dc errors of the wattmeter at unity power factor (making $\sin \theta=0$ ), and the errors entering as " $\tau_{w}$ " may be measured as a group by determining the ac-dc errors of the wattmeter at zero power factor (making $\cos \theta=0$ ). The " $\Delta \alpha$ " errors will also be present in measurements at unity and zero power factor; but since the " $\Delta \alpha$ " errors can be determined independently, corrections can be applied for them.

\section{ERRORS DEPENDING ON $E$ OR $I$ SEPARATELY-" $\Delta \alpha$ "}

(a) INTERACTION BETWEEN PARTS OF VOLTAGE CIRCUIT

If there were appreciable interaction between the moving coils and other parts of the voltage circuit, it would cause a deflection of the moving system when voltage only (either alternating current or direct current) is applied to the wattmeter. In order to detect this effect if present, 100 volts alternating current (a d-c voltage would cause a deflection by reaction with the earth's magnetic field as explained above) were applied to the voltage circuit. No deflections were observed for values of series resistor from 2,000 to $10,000 \mathrm{ohms}$, and it was concluded that this interaction effect is negligible.

\section{(b) MAGNETIC IMPURITIES IN THE MOVING SYSTEM}

Although the utmost care was exercised in selecting materials for and construction of the wattmeter moving system, there is a possibility that the resulting system may contain magnetic impurities. If the magnetic impurity is not symmetrically distributed around the moving-system axis, it will cause the moving system to deflect with current through the fixed coils only. With magnetic impurities, such as "hard iron" filings, which are capable of retaining some magnetism, the deflection of the moving system would not be the same for alternating current in the fixed coils as for direct current and in the case of direct current it would depend on the direction of the current. With magnetic impurities of zero retentivity, the deflection of the moving system would be the same for alternating current as for direct current through the fixed coils but would vary as the square of the magnitude of this current. In measuring a given value of watts, the alternating current will be different from the direct current if (1) the alternating and direct voltages are different or (2) the power factor is other than unity. Thus, even though the magnetic impurities have zero retentivity, the deflection caused by them will not necessarily be the same for equal magnitudes of a-c and d-c watts being measured.

When the present wattmeter was first assembled, one of the tests consisted in putting current through the fixed coils, the moving-coil circuit being open, and noting the deflection of the moving system. Deflections as large as $2 \mathrm{~mm}$ (0.05 percent of normal full-scale deflection) were observed. The magnitude of these deflections varied with the orientation of the moving system with respect to the fixed coils but was independent of the frequency of the current through the fixed coils, indicating that the deflections were caused by magnetic impurities in the moving system. 
The component parts of the moving system (1, moving coils; 2 , mirror; 3, collars and clamps for holding mirrors; 4, collar with adjustable weights for balancing the system; 5 , damping vane; and 6 , Bakelite tube upon which all other parts were mounted) were all made of materials that are normally considered to be nonmagnetic. With the moving system assembled it was impracticable to determine which of the component parts contained magnetic impurities. A new moving system was constructed and each component part was tested for magnetic impurities before assembly. This test consisted in suspending the part, with a small mirror attached to it for reflecting: a beam of light onto a scale, in the field of a strong electromagnet and noting the deflection of the beam of light when the coil of the electromagnet was energized. These tests showed that a Bakelite tube, obtained from the same source as the tube used in the first moving: system, contained considerable magnetic impurities which appeared to be concentrated in a plane containing the central axis of the tube. This would account for the results obtained with the first moving system in the wattmeter. In searching for a substitute for this tube, samples of glass, porcelain, clear Bakelite (no filler), and other resins were tested for magnetic impurities. It was found that these samples contained only very slight magnetic impurities in comparison with a sample of the Bakelite tube used in constructing the first moving system. Thus it was concluded that the filler used in making the Bakelite tube and not the Bakelite itself contained the magnetic impurity. Four samples of Bakelite tube were obtained from separate sources and tested for magnetic impurities. Of these four, one was chosen which contained about the same amount of magnetic impurity as the glass or porcelain, and a new moving system was constructed using a tube of this material for mounting the moving-system parts. Before mounting each component part on the new moving system, the system was suspended in the wattmeter and its deflection was noted with current through the fixed coils only. At each stage of construction this deflection was just barely noticeable with rated current through the fixed coils. When the moving system was completed, twice-rated current was passed through the fixed coils and measurable deflections of the moving system were obtained. The moving coils were then twisted around on the Bakelite tube until the position of zero mutual inductance between the fixed and moving coils (the position near which the moving coils are held when the wattmeter is in use) coincided with the position for minimum deflection of the moving system with current through the fixed coils only. The deflection of the moving system at this position was found to be about 0.2 $\mathrm{mm}$ (0.005 percent of normal wattmeter deflection) with twice-rated current through the fixed coils. Thus it was concluded that the error due to magnetic impurities would be negligible with rated current through the fixed coils.

\section{c) INDUCED AND CAPACITANCE CURRENTS IN THE MOVING SYSTEM}

The effects of induced and capacitance currents in the moving: system increase as the frequency of the fixed-coil current is increased, and although they are entirely negligible at power frequencies (as shown in the tests made to detect magnetic impurities in the moving system) they may become measurable at frequencies above $1,000 \mathrm{c} / \mathrm{s}$. They may be detected by passing high-frequency current through the 
fixed coils with the moving coils open-circuited and noting any deflection of the moving system. When rated current at a frequency of $2,000 \mathrm{c} / \mathrm{s}$ was passed through the fixed coils, deflections of the moving system as large as $1 \mathrm{~cm}$ were obtained. These deflections are the result of a combination of the following effects: (1) eddy currents within the thickness of the wires forming the individual turns of the moving coils, (2) eddy currents in other parts of the moving system, such as the damping vane, and (3) capacitance currents flowing in some of the moving-coil turns and through the capacitance existing between the fixed and moving coils.

The summation of the torques produced by eddy currents in individual turns of the moving coils tends toward zero and would be exactly zero with the moving coils in the position of zero mutual inductance with the fixed coils if the fixed-coil flux were uniform throughout the area occupied by the moving coils. Any torque produced in the present wattmeter by the eddy currents in the moving coils may be combined with the torques produced by eddy currents in other moving parts of the wattmeter, since the torques due to all these eddy currents are similar functions of the same variables.

The three effects causing the deflections noted above may now be considered as two: (1) eddy currents in moving system, and (2) capacitance currents flowing in some of the moving-coil turns. The deflection due to eddy currents will (a) increase approximately as the square of the frequency of the fixed-coil current, (b) increase as the square of the current through the fixed coils; but it will be independent of (a) the efficacy of the shield between the fixed and moving coils, (b) the location of the electrostatic tie between the fixed and moving coils, and (c) the connection of the fixed coils (series, series-parallel, or parallel). The deflection due to capacitance currents will (a) increase approximately as the square of the frequency of the fixedcoil current, (b) increase as the square of the current through the fixed coils, (c) depend upon the efficacy of the shield between the fixed and moving coils, (d) be approximately unchanged in magnitude but reversed in direction when the electrostatic tie between fixed and moving coils is changed from one terminal of the fixed coils to the other terminal, and (e) depend upon the fixed-coil connections, being largest for series and least for parallel. The total deflection caused by eddy currents and capacitance currents may be separated into its two components by use of relation (d). For a given magnitude and frequency of fixed-coil current the deflection of the moving system was noted with (1) the \pm or $b$ terminal of the moving coils connected to terminal $a$ (see fig. 5) of the fixed coils, (2) the $b$ terminal of the moving coils connected to terminal $b$ of the fixed coils. The algebraic mean of these two deflections is the deflection caused by eddy currents, and one-half the algebraic difference between these two deflections is the deflection caused by capacitance currents.

From tests performed on the wattmeter with rated current at a frequency of $2,000 \mathrm{c} / \mathrm{s}$ through the fixed coils, the deflections due to eddy currents in the moving system and capacity currents in the moving coils were determined and the results are shown in table 1 . These tests were performed with the shield between the fixed and moving coils tied to the \pm side of the moving-coil circuit as shown in figure 5 . With this shield "floating," the deflections due to capacitance currents were found to be about three times those given in the table. 
TABLE 1.-Wattmeter deflections due to eddy currents and capacity currents

[Moving-coil circuit opened. Fixed-coil current frequency, 2,000 cycles. Shield tied to moving coil terminal $b$.]

\begin{tabular}{|c|c|c|c|c|c|}
\hline Fixed coil-connections & $I_{0}$ & MC terminal $b$ tied to & $\begin{array}{l}\text { Total wat- } \\
\text { meter de- } \\
\text { flection }\end{array}$ & $\begin{array}{l}\text { Deflection } \\
\text { due to } \\
\text { eddy cur- } \\
\text { rents }\end{array}$ & $\begin{array}{l}\text { Deflection } \\
\text { due to } \\
\text { capaci- } \\
\text { tance } \\
\text { currents }\end{array}$ \\
\hline Series.. & $\begin{array}{r}a m p \\
2.5\end{array}$ & $\left\{\begin{array}{l}\mathrm{FC} \quad a_{\ldots} \\
\mathrm{FC} \quad b_{\ldots} . .\end{array}\right.$ & $\begin{array}{l}c m \\
0.47 \\
1.04\end{array}$ & $\begin{array}{l}\mathrm{cm} \\
0.76\end{array}$ & $\begin{array}{l}\mathrm{cm} \\
0.28\end{array}$ \\
\hline Series-parallel... & 5 & $\left\{\begin{array}{l}\mathrm{FC} \quad a_{1} \\
\mathrm{FC} \quad b_{2}\end{array}\right.$ & $\begin{array}{r}0.50 \\
.86\end{array}$ & .68 & .18 \\
\hline Parallel.... & 10 & $\left\{\begin{array}{l}\mathrm{FC} a \\
\mathrm{FC} b\end{array}\right.$ & $\begin{array}{l}.56 \\
.75\end{array}$ & .66 & .09 \\
\hline
\end{tabular}

The deflection of about $0.70 \mathrm{~cm}$ given in table 1 as due to eddy currents in the moving system seemed quite large. In order to determine which part of the moving system contained these eddy currents, a coil was placed near the wattmeter in such a position that, with a given value of current at $2,000 \mathrm{c} / \mathrm{s}$ passing through this coil, the magnetic field strength at the damping vane would be about the same as that produced by the wattmeter fixed coils at rated current and the magnetic field strength at other parts of the moving system would be low. With current flowing through this external coil and no current through the wattmeter coils, the deflection of the moving system was found to be about $0.50 \mathrm{~cm}$. Thus it appears that most of the deflection due to eddy currents in the moving system is caused by eddy currents in the damping vane. In constructing another wattmeter, it would be advisable either to increase the distance between the damping vane and wattmeter coils or to use as a damping vane some nonconducting material, coated with a very thin conducting film to eliminate accumulation of static charge.

Another possible source of induced currents in the moving system is the mutual inductance between the fixed and moving coils. These induced currents will flow only when the moving-coil circuit is closed and when the position of the moving system is not at the point of zero mutual inductance. With the moving system displaced 2 degrees of arc (a deflection of $15 \mathrm{~cm}$ on the scale) from the point of zero mutual inductance and with rated current at a frequency of $2,000 \mathrm{c} / \mathrm{s}$ through the fixed coil, a deflection of $0.50 \mathrm{~cm}$ was noted when the moving-coil circuit was closed through an external resistance of 1,000 ohms (without a compensating capacitance). With positions of the moving system at which the wattmeter is generally used (within about $2 \mathrm{~cm}$ of the deflection at zero mutual inductance), no noticeable deflection was obtained when the moving-coil circuit was closed through a resistance of $1,000 \mathrm{ohms}$.

The only appreciable error, entering eq 1 as " $\Delta a$ ", was found to be that due to eddy currents in the moving system and capacitance currents in the moving coils. The magnitude of this error was measured at various frequencies up to $3,000 \mathrm{c} / \mathrm{s}$ with $5 \mathrm{amp}$ through the fixed coils connected in series-parallel and with the moving-coil circuit open, the shield and moving-coil terminal $b$ being tied to fixedcoil terminal $b$. The results of these measurements are shown by the curve plotted in figure 8 . By means of these results the " $\Delta \alpha$ " 
errors can be separated from the total ac-dc errors measured in the experiments to be described.

\section{ERRORS DEPENDING UPON EI-TEST AT UNITY POWER-FACTOR}

\section{(a) METHOD}

A simple and convenient way to obtain unity power-factor conditions on the wattmeter is to connect it for use as an ammeter, as shown in figure 7 . For these connections, the current in the moving
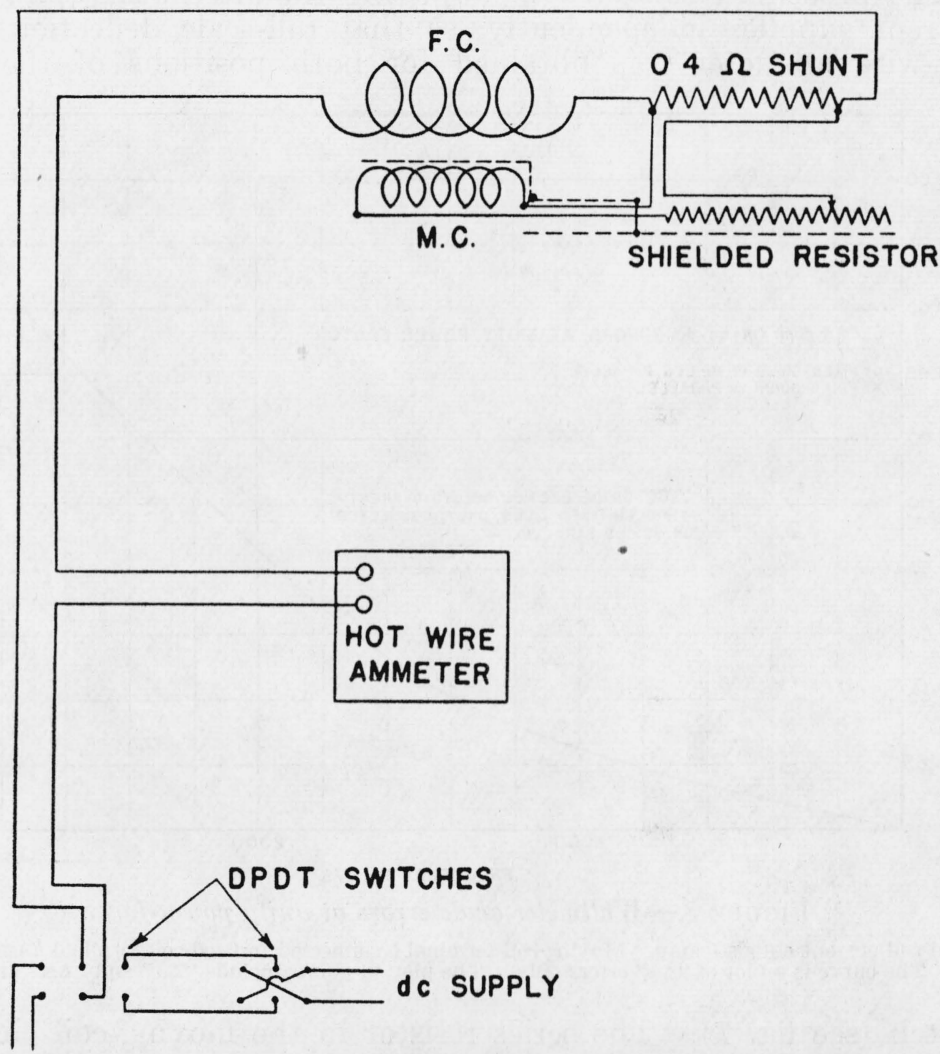

OC SUPPLY

FIGURE 7.-Electric connections for comparing the wattmeter, connected as an ammeter, with a hot-wire ammeter at unity power-factor.

coil may be considered to be in phase with the current through the fixed coil. Any slight difference in phase $(\tau)$ between these currents will enter into the results as an error equal to $100(1-\cos \tau)$ in percent, and the conditions to be fulfilled in order to make the error negligible are easily attainable. Thus the only ac-dc errors entering this unity power-factor test will be those designated as " $\Delta m$ " and " $\Delta \alpha$ " in eq 1 , and these errors will be equivalent to the errors of the wattmeter when it is used to measure power at unity power-factor, provided the moving-coil circuit is properly shielded. 
The main reason for connecting the wattmeter as an ammeter to measure its ac-dc errors at unity power-factor ${ }^{8}$ was that a 5 -amp Hartman \& Braun hot-wire ammeter, which was constructed for the accurate measurement of radio-frequency currents, was readily obtainable and convenient to use as a standard. It was assumed that the ac-dc errors of the ammeter are negligible for frequencies up to $3,000 \mathrm{c} / \mathrm{s}$.

\section{(b) PROCEDURE}

The procedure consisted in adjusting the alternating- and directcurrent supplies independently, so that full-scale deflection of the hot-wire ammeter was obtained for both positions of the ac-dc

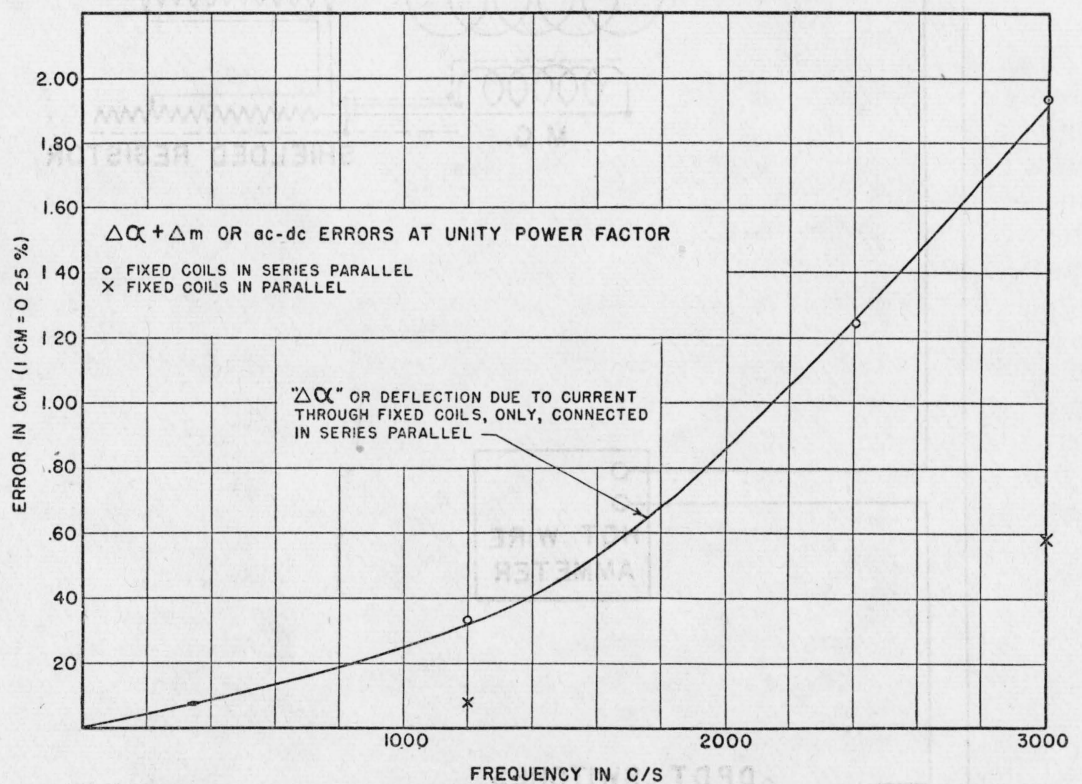

FIgURe 8.-Wattmeter ac-dc errors at unity power-factor.

Fixed-coil current equals 5 amp. Moving-coil terminal $b$ connected to fixed-coil terminal $b$ (see fig. 5 ). The curve is a plot of " $\Delta \alpha$ " errors only. The plotted points include " $\Delta \alpha$ " and " $\Delta m$ " errors.

switch (see fig. 7). The series resistor in the moving-coil circuit of the wattmeter was adjusted to bring the wattmeter deflection to normal full-scale position (this required about $1,300 \mathrm{ohms}$ in the moving-coil circuit), and the current was left on for one-half hour to allow both instruments to come to temperature equilibrium. The test data were taken in the following order: (1) with alternating current of the desired frequency on, the value of current was adjusted to give full-scale deflection on the hot-wire ammeter and the deflection of the wattmeter was read; (2) with direct current on and adjusted to duplicate the setting on the hot-wire ammeter, the deflection of the wattmeter was read; (3) with direct current reversed, another reading of wattmeter deflection was obtained; and (4) with alternating current on, the first step was repeated. The difference between the average a-c (steps 1 and 4 above) and the average d-c

\footnotetext{
8 A quadrant electrometer connected to measure power could be used as a standard instrument for this purpose, but a considerable amount of time and patience would be required to set up and calibrate an instrument of this type so that the desired accuracy could be attained.
} 
(steps 2 and 3 above) wattmeter deflections is a measure of the wattmeter ac-dc errors at unity power-factor.

The accuracy of the measurements is limited by the ability of the observer to repeat settings on the hot-wire ammeter. By using an instrument-reading camera focused directly on the pointer and adjusting current until the image of the pointer edge coincides with a fine line on the ground-glass screen of the camera, settings can be repeated to within 0.025 of a scale division. Since each value of ac-dc difference was the average of several sets of data, the accuracy of these average values was considered to be within about 0.01 of a scale division or 0.01 percent (settings were all made at the 100division point).

\section{(c) RESULTS}

For the purpose of comparison the results of these tests have been entered in figure 8. As already noted, the curve in this figure is a plot of the wattmeter deflection " $\triangle \alpha$ " against frequency, obtained on a previous test with $5 \mathrm{amp}$ through the wattmeter fixed coils connected in series-parallel and the moving-coil circuit open (this is the deflection due to eddy currents in the moving system and capacitance currents in the moving coils). The plotted points on this figure represent the values of ac-dc errors of the wattmeter at unity power-factor obtained by the tests just described. The agreement of the plotted points with the curve (with the fixed coils connected in parallel only one-half of rated current was used and the ac-dc error is correspondingly less) indicates that for frequencies up to $3,000 \mathrm{c} / \mathrm{s}$ the ac-dc errors of the wattmeter at unity power-factor are due only to eddy currents in the moving system and capacitance currents in the moving coils. These errors enter into eq 1 as the term " $\triangle \alpha$ ". The error designated as " $\triangle m$ " in this equation is thus found to be negligible (less than 0.01 percent) for frequencies up to $3,000 \mathrm{c} / \mathrm{s}$.

\section{ERRORS DEPENDING UPON PHASE ANGLE $\theta$-TESTS AT ZERO POWER-FACTOR}

The ac-dc errors of the wattmeter entering eq 1 as a phase defect " $\tau_{w}$ " will appear only when the wattmeter is used at power factors other than unity, and their effect will be maximum at zero powerfactor. Possible sources of phase defect are (1) eddy current or skin effects in the fixed coils, (2) capacitance currents in the fixed coils, and (3) phase defect in the voltage circuit. Since the phase defect introduced by these sources of error increases as the frequency increases, it was decided to determine the phase defect at several frequencies. Tests were made at $60 \mathrm{c} / \mathrm{s}$ using a quadrant electrometer and at $500,1,000$, and $2,000 \mathrm{c} / \mathrm{s}$ using mica capacitors.

(a) AT 60 CYCLES PER SECOND, USING QUADRANT ELECTROMETER

(1) Method.

The source of current and voltage consisted of two alternators driven by a direct-current motor, the shafts of all these machines being: coupled together. The motor was supplied from storage batteries, and the speed was adjusted to give a 60 -cycle output from each generator. The output voltage of each alternator and the phase angle between their voltages could be varied independently. One alternator was used to supply the voltage circuit of the standard wattmeter, and this 
same voltage was connected between the case and the needle of the quadrant electrometer. The other alternator was used to supply the current through the fixed coils of the wattmeter, and by also passing this current through a shunt and then stepping-up the drop across the shunt by means of a voltage transformer whose secondary was connected to the quadrants of the electrometer, a voltage was applied to the quadrants which bore a fixed relation to the current through the wattmeter fixed coils.

The voltage, $E$, from one of the alternators and the current, $I$, from the other alternator correspond to a value of power $E I \cos \theta$ which

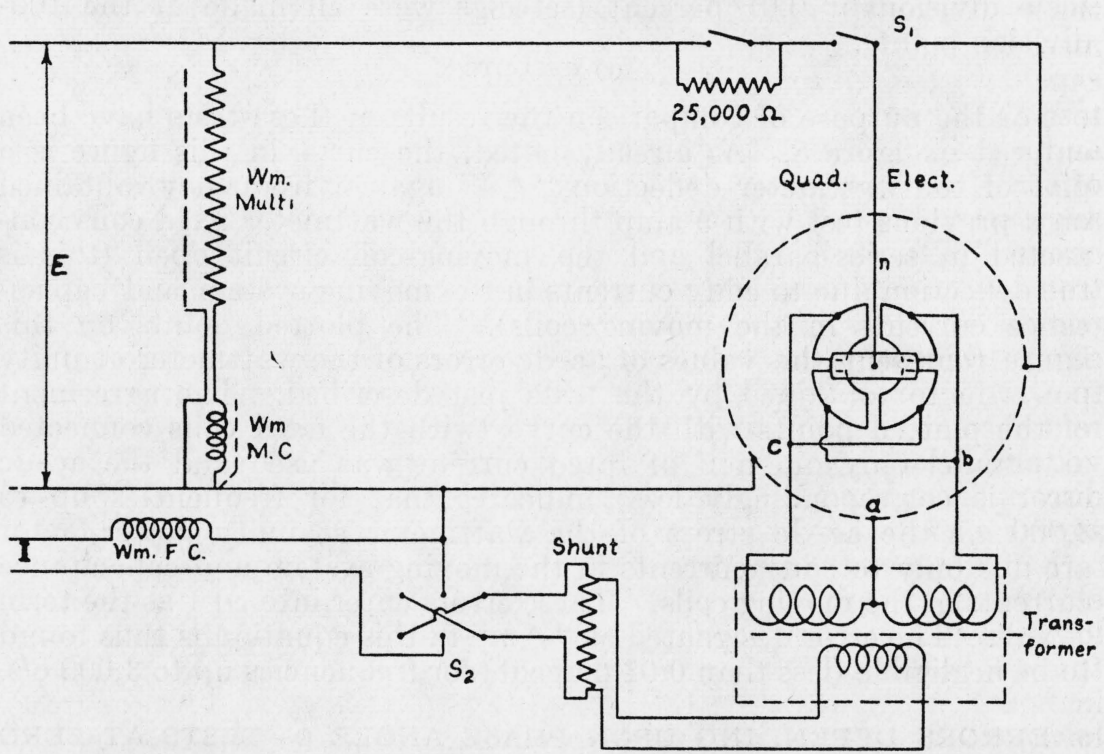

FiguRE 9.-Electric connections for comparing the wattmeter with a quadrant electrometer at zero power-factor.

$R=$ resistance of shunt.

$\boldsymbol{L}=$ inductance of shunt.

$r=$ resistance of shunt potential leads.

$R_{t}=$ effective resistance of transformer primary winding.
$L_{\mathrm{t}}=$ effective inductance of transformer primary winding.

$I_{t}=$ transformer primary current.

$I_{\mathrm{t}}=$ transformer primary current.
$E_{1}=$ transformer primary voltage.

$E_{\mathrm{c}}=$ transformer secondary voltage from $a$ to $c$. $E_{\mathrm{b}}=$ transformer secondary voltage from $a$ to $b$

can be measured independently by the wattmeter and by the electrometer. The phase angle, $\theta$, between the voltage and current was adjusted until the electrometer indicated zero power. The wattmeter would then be expected to indicate the power corresponding to 90 degrees minus the phase difference between the current through the fixed coils of the wattmeter and the quadrant voltage of the electrometer. A derivation of the value of this phase difference is given in appendix II. Any discrepancy between the actual power indicated by the wattmeter and the power computed from this phase difference is considered to be caused by a phase defect in the wattmeter, and the wattmeter phase-defect was computed on this basis.

(2) Procedure.

The wiring diagram in figure 9 was followed in connecting the wattmeter and electrometer for the test at zero power-factor. The voltage, $E$, was set at 150 (within 0.2 of a volt) by adjusting the field of the 
alternator. The current, $I$, was set at $2.5,5$, or $10 \mathrm{amp}$ (within 0.2 percent), depending upon whether the series, series-parallel, or parallel connection, respectively, of the wattmeter fixed coils was being used. The nominal value of the shunt corresponding to these currents was $0.8,0.4$, or $0.2 \mathrm{ohm}$, respectively, thus keeping the primary voltage of the transformer 2 volts for all tests. The secondary voltage across each half of the winding was approximately 25 volts. The connection from the transformer secondary to the quadrant of the electrometer was a two-conductor shielded lead, the shield being connected to the transformer shield and the midpoint of the winding at one end and to the electrometer case at the other end. The same leads were used in measuring the ratio and phase angle of the transformer so that any capacitance load imposed by the leads would be the same in both the test and the use of this transformer. The phase angle, $\theta$, between $E$ and $I$ was adjusted to approximately 90 degrees by rotating the stator of the alternator supplying the current. A fine control of this phase angle was obtained by inserting a variable self-inductor in the current circuit. The $25,000-\mathrm{ohm}$ resistor in series with the lead to the electrometer needle was inserted to protect the needle suspension from possible short circuits between needle and quadrant during preliminary adjustments. For final readings this resistor was shorted out to reduce to a minimum any voltage drop in this lead due to capacitance currents. A switching arrangement was placed in the current and voltage supply such that the alternating current and voltage could be disconnected and a direct current and voltage substituted. The d-c supply was used to calibrate the wattmeter.

The detailed procedure in checking the wattmeter against the electrometer at zero power-factor will now be described in chronological order. The electrometer was set on a stable platform with the needle centrally located with respect to the quadrants, as indicated in figure 9. A light source was located in such a position that the beam reflected from the mirror mounted on the electrometer suspension was focused on a ground-glass scale located about $2 \mathrm{~m}$ from the electrometer. The leveling screws of the electrometer were adjusted until the mechanical and electrical zeros of the electrometer coincided (to within $2 \mathrm{~mm}$ ), that is, with current off and a-c voltage adjusted to $150 \mathrm{v}$ the electrometer reading did not change when switch $S_{1}$ was thrown from right to left. The zero readings of both the electrometer and the wattmeter were recorded with no current flowing and $E=150$ $\checkmark$ a-c. The current supply was connected and current adjusted to $2.5,5$, or 10 amp a-c depending on the fixed-coil connections of the wattmeter. Frequency was set to $60 \mathrm{c} / \mathrm{s}$ and voltage was reset if necessary. The phase angle between $E$ and $I$ was adjusted until the electrometer reading was the same as its zero, and the reading of the wattmeter was recorded. The current supply was disconnected and zero readings of electrometer and wattmeter were recorded. The setting of the electrometer with current on should agree with the average of the two electrometer zero readings (in the few cases where this was not true the readings were discarded). The above procedure was repeated with switch $S_{2}$ in the reversed position. The a-c supply was disconnected and the d-c supply was connected, the voltage being adjusted to $150 \mathrm{v}$. The direct current was adjusted until the wattmeter reading was equal to the average of the two readings obtained 
with alternating current. The value of direct current was recorded, direct voltage and current were reversed, and another value of direct current was obtained and recorded. The entire procedure outlined above was repeated with the alternating voltage supply connections reversed. The average of the four values of direct current thus obtained divided by the alternating current gives $\cos \theta$, which should equal $1 / 2 \sin \left(2 \delta+\beta_{c}+\beta_{b}\right)^{9}$ if there is no phase defect in the wattmeter.

(3) Results.

TABLE 2.-Wattmeter phase defect at $60 \mathrm{c} / \mathrm{s}$

[This table is not a complete list of all data taken at 60 cycles. The values shown were chosen to indicate the range of variation in $\tau_{w}$. The average value of all determinations of $\tau_{w}$ at 60 cycles is 0.2 minute]

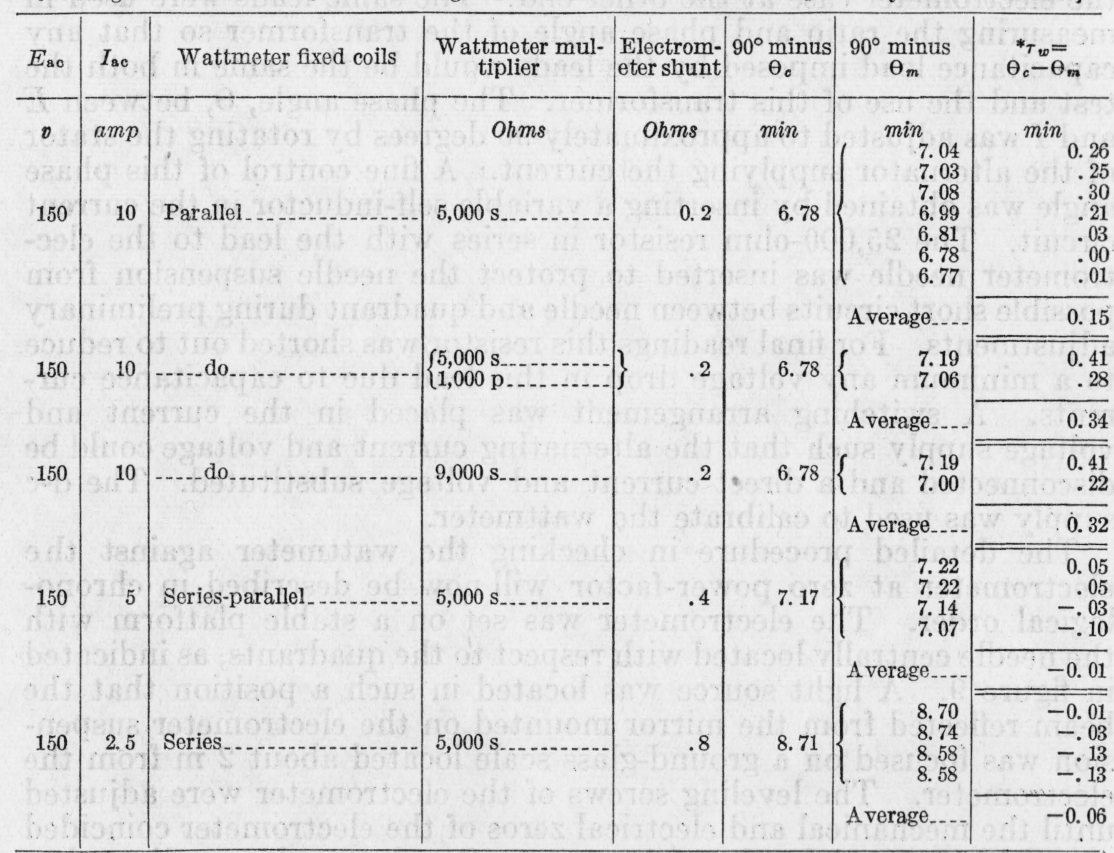

* A positive value of $\tau_{w}$ indicates that the moving coil current leads the supply voltage.

The results of tests at zero power-factor comparing the wattmeter with a quadrant electrometer are tabluated in table 2 . The phase defect of the wattmeter is indicated as the difference between two phase angles (1) $\theta_{c}$ which is 90 degrees minus the computed phase angle between the current through the wattmeter fixed coils and the voltage across the quadrants of the electrometer, and (2) $\theta_{m}$ which is the power-factor angle measured with the wattmeter while the quadrant electrometer indicated zero watts. The wattmeter phase defect, $\tau_{w}$; probably consists of two components (1) a phase displacement between the moving-coil current and the voltage applied to the wattmeter voltage circuit, and (2) a phase displacement between the magnetic flux due to the fixed coils and the current supplied to the fixed coils. For convenience in discussing the phase defect, the two components are added and this total phase defect is treated as if it were a phase displacement between the moving-coil current and the wattmeter supply voltage; a positive value of $\tau_{w}$ indicates that the moving-coil current leads the supply voltage. The computed phase angle, $\Theta_{c}$,

\footnotetext{
${ }^{9}$ For the derivation of this relation see appendix II.
} 
was primarily dependent upon the phase angle of the potential transformer. The phase angle of this transformer had an uncertainty of \pm 0.1 minute, probably due to magnetic instability of the core. The experimental error in comparing the wattmeter and the electrometer was \pm 0.1 minute. Thus the total uncertainty in $\tau_{w}$ was \pm 0.2 minute, which is sufficient to account for the variations of the phase defect of the wattmeter as indicated in the last column of table 2. The conclusion is that the phase defect of the wattmeter at a frequency of $60 \mathrm{c} / \mathrm{s}$ is very probably less than 0.4 minute for any fixed-coil connection and for any arrangement of the multiplier circuit as normally used.

\section{(b) AT HIGH FREQUENCIES, USING CAPACITANCE LOAD}

\section{(1) Method and Procedure.}

By passing current through the fixed coils of the wattmeter and a capacitor, connected in series, and applying the voltage drop across the capacitor to the voltage circuit of the wattmeter, the current and voltage of the wattmeter will be very nearly 90 degrees out of phase and the wattmeter deflection should be about zero. The small value of watts indicated by the wattmeter will be due to (1) any phase defect in the capacitor used as a load; (2) the current taken by the voltage circuit of the wattmeter, which necessarily flows through the wattmeter fixed coils; (3) the current taken by the voltmeter used to measure the drop across the capacitor; and (4) any phase defect in the wattmeter. Since the total watts indicated by the wattmeter can be determined and the first three of the above factors making up the total watts can be computed or measured, the fourth factor (wattmeter phase defect) can be deduced.

The capacitance used as a load on the wattmeter must have a value such that with the normal wattmeter voltage across it (about $150 \mathrm{v}$ ), the current taken will be equal to the rated current of the wattmeter fixed coils $(2.5,5$, or $10 \mathrm{amp})$. It would be almost impossible to build up enough capitance by using air capacitors. Paper capacitors have losses too large and too unstable. Mica capacitors were considered feasible for this work, and the largest capacitance which could be built up from all of the mica capacitors readily available was about $10 \mu \mathrm{f}$. With these capacitors it was possible to test the wattmeter at frequencies of 500 to $2,000 \mathrm{c} / \mathrm{s}$. It was decided to measure the phase defect of the wattmeter at 500,1,000, and 2,000 $\mathrm{c} / \mathrm{s}$ and then if possible to extrapolate the results back to lower frequencies.

The wiring diagram for the equipment used in this test is shown in figure 10. A Kelvin voltmeter of the multicellular electrostatic type was used to measure the voltage across the wattmeter voltage circuit, because the deflection of this type of voltmeter is independent of frequency over a wide range. A resistance voltage divider was used in conjunction with this voltmeter to extend its range, since the maximum voltage which could be read on the voltmeter alone was $120 \mathrm{v}$. An attempt was made to extend the range of this voltmeter by putting an air capacitor in series with it, but this plan had to be abandoned because of an error introduced by dielectric losses in the voltmeter.

With switch $S_{2}$ (see fig. 10 ) thrown to the right-hand position the wattmeter measures the power loss in capacitor $C$, the power consumed in $r_{m}$ and $r_{v}$, and an additional quantity $\omega C E^{2} \sin \tau_{w}$, where $\tau_{w}$ is 
the phase defect of the wattmeter. With switch $S_{2}$ thrown to the left-hand position the wattmeter measures the power consumed in $r_{m}, r_{0}$, and $R$. Under these conditions the current through the wattmeter fixed coils is small in value compared to the large capacitance current taken by $C$ and is in phase with the voltage, $E$, across the wattmeter voltage circuit, so that the effect of the wattmeter phase defect is negligible. The procedure followed in measuring the wattmeter phase defect, $\tau_{w}$, was first to set the supply frequency and voltage with switch $S_{2}$ in the right-hand position and read the wattmeter deflection, then to duplicate the setting of supply frequency

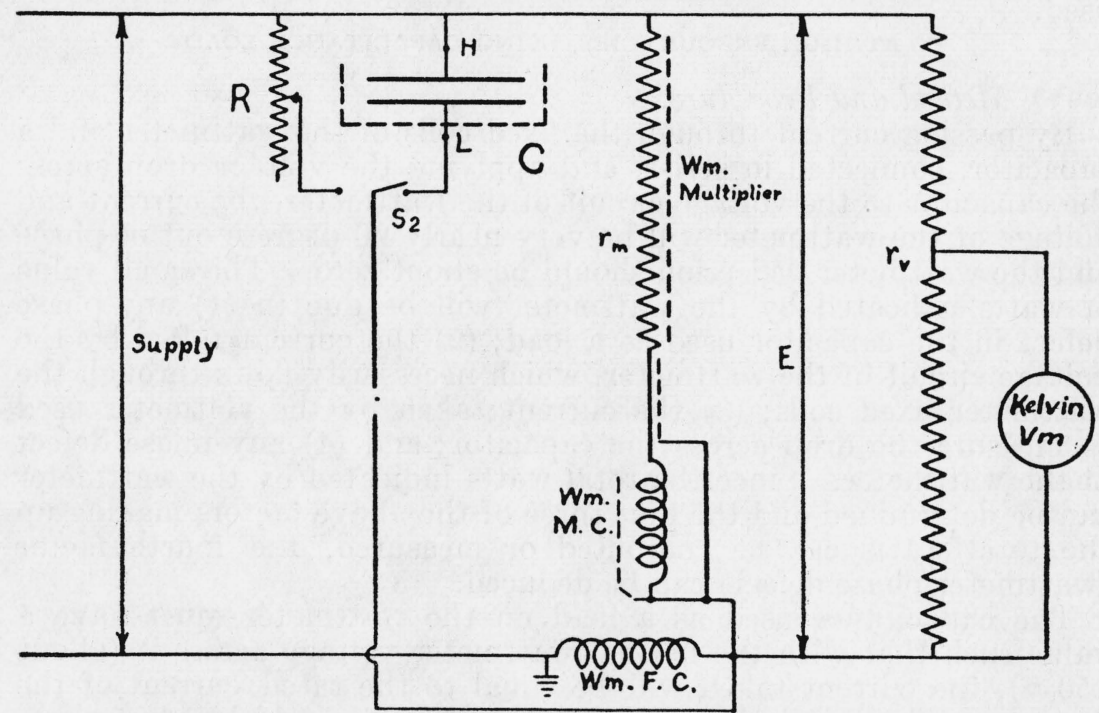

FIGURE 10.-Electric connections for measuring wattmeter phase defect at high frequencies using a capacitance load.

$C=$ mica capacitor.

$R=$ adjustable resistor.

$r_{m}=$ resistance of wattmeter voltage circuit. $r_{0}=$ resistance of voltage divider for electrostatic

$E=\begin{aligned} & \text { voltmeter. } \\ & \text { voltage applied to wattmeter voltage circuit. }\end{aligned}$

and voltage with $S_{2}$ in the left-hand position and adjust the resistor, $R$, until the wattmeter deflection was the same as just read. The wattmeter phase defect can then be deduced from the value of the resistor, $R$, capacitor, $C$, and phase defect, $\tau_{\mathrm{e}}$, of capacitor $C$.

(2) Derivation of Equation.

By referring to the wiring diagram in figure 10 and using the notation indicated on the diagram, two equations for the quantity measured by the wattmeter can be written. When the capacitor, $C$, is used as a load on the wattmeter (switch $S_{2}$ to the right) the quantity is

$$
P_{\mathrm{o}}=\omega C E^{2} \sin \left(\tau_{c}+\tau_{w}\right)+\frac{E^{2}}{r_{m}}+\frac{E^{2}}{r_{v}} .
$$

When the resistor, $R$, is used as a load on the wattmeter (switch $S_{2}$ to the left), this quantity is

$$
P_{R}=\frac{E^{2}}{r_{n}}+\frac{E^{2}}{r_{v}}+\frac{E^{2}}{R}
$$


During the tests, the voltage, $E$, and the deflection of the wattmeter were held constant for the two loads on the wattmeter. Thus $P_{c}=P_{R}$, and the two equations give

$$
\omega C \sin \left(\tau_{c}+\tau_{w}\right)=\frac{1}{R}
$$

and since $\tau_{c}$ and $\tau_{w}$ are small angles,

$$
\sin \tau_{v o}=\frac{1}{R \omega C}-\sin \tau_{c} .
$$

(3) Results.

The results of these tests are shown in figure 11 as a plot of wattmeter phase defect against frequency. The error $(\Delta \alpha)$ due to induced currents in the moving system and capacitance currents in the moving coils is present in the results shown, but its magnitude (a maximum of 2 minutes at $2,000 \mathrm{c} / \mathrm{s}$ ) was not sufficient to be taken into account. The possible sources of this phase defect are (1) eddy current or skin effects in the fixed coils, (2) phase defect in the voltage circuit, and (3) capacitance currents between turns of the fixed coils and from fixed coils to shield. Possible source of error (3) would cause a phase defect proportional to the square of the frequency, but the results show the phase defect to be directly proportional to frequency; also, when performing the tests, a $0.005-\mu f$ capacitor connected across the fixed coils was found to have no noticeable effect on the phase defect. Therefore, it may be concluded that source of error (3) is negligible for frequencies up to $2,000 \mathrm{c} / \mathrm{s}$. Sources of error (1) and (2) would cause a phase defect directly proportional to frequency. Since the observed phase defect was found to vary in this manner (up to $2,000 \mathrm{c} / \mathrm{s}$ ), it may be concluded that it is the result of one or both of these two effects.

A computation of the part of this phase defect caused by source (2), based on the estimated values of capacitance between parts of the voltage circuit, indicated that part of the wattmeter phase defect can be accounted for by the capacitance currents in the series resistor. The remainder of the wattmeter phase defect must be due to "skin effects" in the fixed coils. The relative magnitude of these two components of the total wattmeter phase defect cannot be definitely stated.

Since the results shown in figure 11 indicate that the wattmeter phase defect is directly proportional to frequency between 500 and $2,000 \mathrm{c} / \mathrm{s}$, it is fairly safe to extend this curve to $60 \mathrm{c} / \mathrm{s}$ and obtain an extrapolated value of phase defect of 0.38 minute. This extrapolated value checks the actual value $(0.2 \text { minute })^{10}$ obtained at $60 \mathrm{c} / \mathrm{s}$, using the quadrant electrometer, within the limits of accuracy $( \pm 0.2$ minute) of the measured value.

\section{SUMMARY}

The electrodynamic instrument described in this paper can be used as a standard wattmeter or ammeter and as a standard ac-dc transfer instrument in testing wattmeters or ammeters. The current range is from 0.25 to $10 \mathrm{amp}$. The voltage range is from 25 to $300 \mathrm{v}$. The

${ }_{10}$ This value is an average of all the data taken at $60 \mathrm{c} / \mathrm{s}$. 
results obtained from this instrument are accurate within 0.01 percent when it is used at power frequencies. The only correction which must be applied to obtain this accuracy is the one due to the phase defect

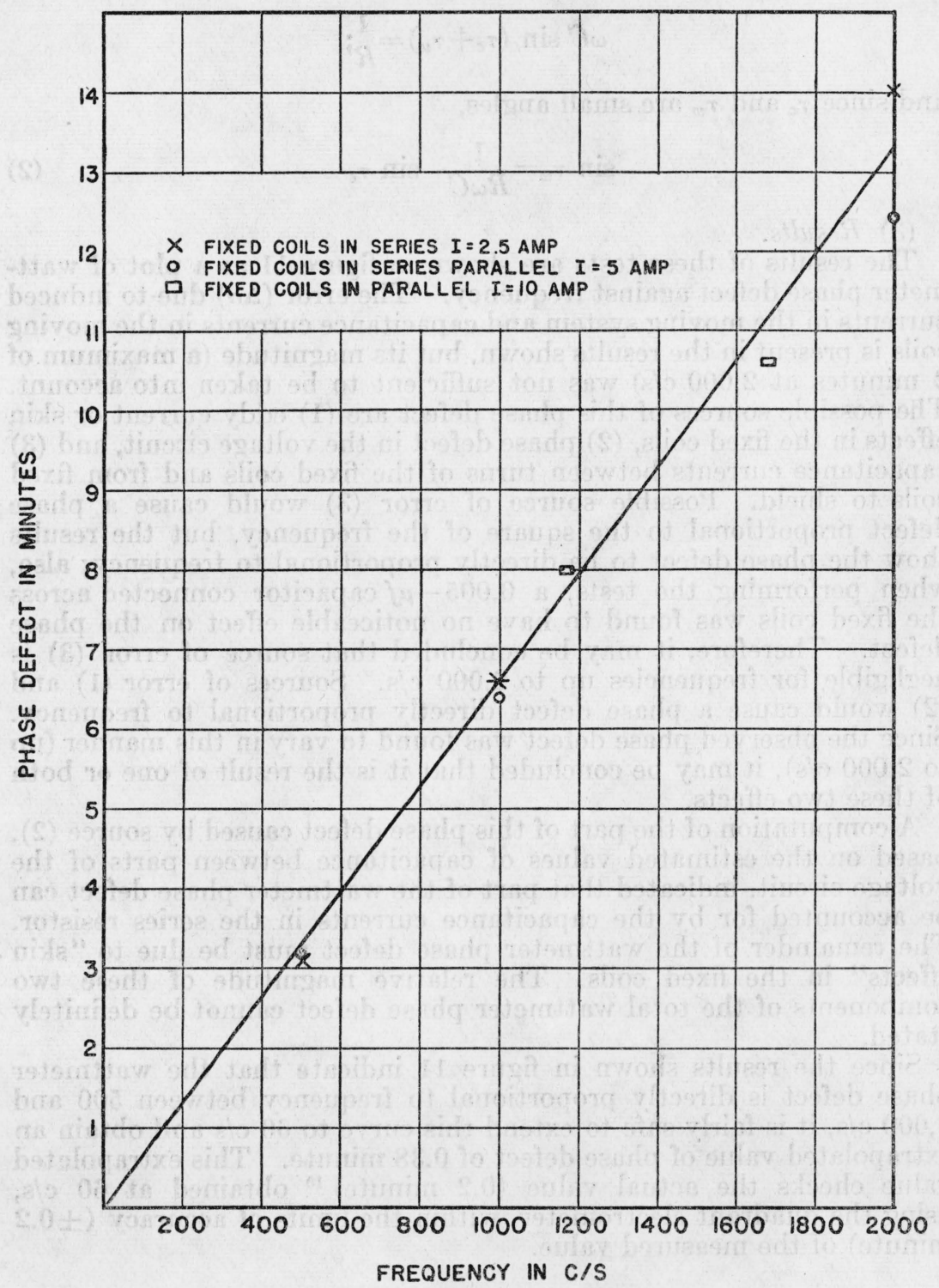

Figure 11.-Plot of wattmeter phase defect against frequency.

Results obtained from tests using a capacitance load.

( 0.38 minute at $60 \mathrm{c} / \mathrm{s})$. This correction will be negligible for power factors greater than 0.7. The instrument can also be used at frequencies up to $2,000 \mathrm{c} / \mathrm{s}$, provided the necessary corrections as described in this paper are applied. 
Almost all the construction of this transfer instrument was done by E. A. Tibbals, one of the Bureau's mechanicians, who is responsible for many valuable suggestions relating to the design of important details of the instrument.

\section{APPENDIX I}

\section{Computation of the Effect of Variation in Wattmeter Sensitivity}

The wattmeter deflection in terms of $S$, wattmeter sensitivity (equal to $G / U$ as defined on page 559); $i$, moving-coil current in milliamperes; and $I$, fixed-coil current in amperes is

$$
\alpha=S i \frac{I}{I \text { (rated). }}
$$

The power being measured is proportional to $I i$, and $I$ (rated) is constant for a given connection of the fixed coils. Thus the deflection may be expressed as

$$
\alpha=K S W \text {, }
$$

where $K$ is a constant and $W$ is the power being measured. If $\alpha_{a}, S_{a}$, and $W_{a}$ denote values with alternating current and voltage; $\alpha_{d}, S_{d}, W_{d}$ denote values with direct current and voltage; $\alpha_{r}, S_{r}, W_{r}$ denote values with direct current and voltage in the reverse direction

$$
\begin{aligned}
& \alpha_{a}=K S_{a} W_{a}, \text { or } W_{a}=\frac{\alpha_{a}}{K S_{a}} ; \\
& \alpha_{d}=K S_{d} W_{d}, \text { or } W_{d}=\frac{\alpha_{d}}{K S_{d}^{\prime}} ; \\
& \alpha_{r}=K S_{r} W_{r} \text {, "or } W_{r}=\frac{\alpha_{r}}{K S_{r}}
\end{aligned}
$$

The relation to be obtained is the ratio of $W_{a}$ to the average d-c power in terms of the $\alpha$ 's and S's.

$$
\frac{2 W_{a}}{W_{d}+W_{r}}=1+\frac{W_{a}-\frac{1}{2}\left(W_{d}+W_{r}\right)}{\frac{1}{2}\left(W_{d}+W_{r}\right)}=1+\delta .
$$

Substituting values of $\alpha$ and $S, \delta$ becomes

$$
\delta=\frac{\frac{\alpha_{a}}{K S_{a}}-\frac{1}{2 K}\left(\frac{\alpha_{d}}{S_{d}}+\frac{\alpha_{r}}{S_{r}}\right)}{\frac{1}{2 K}\left(\begin{array}{c}
\alpha_{d} \\
S_{d}^{-}
\end{array}+\frac{\alpha_{r}}{S_{r}}\right)}
$$

Since $S_{d}$ and $S_{r}$ differ but slightly from $S_{a}$, by putting $S_{d}=S_{a}+s_{d}$ and $S_{r}=$ $S_{a}+s_{r}$ the above equation simplifies to

$$
\delta=\frac{\alpha_{a}-\frac{\alpha_{d}+\alpha_{r}}{2}}{\frac{\alpha_{d}+\alpha_{r}}{2}}+\frac{1}{2}\left(\frac{s_{r}+s_{d}}{S_{a}}\right)
$$

One hundred times the first term on the right side of the above equation gives the percentage excess of a-c power over average d-c power as normally computed assuming constant sensitivity. One hundred times the second term gives the correction in percentage to be applied when the sensitivity for $\alpha_{d}$ and $\alpha_{r}$ are different from the sensitivity for $\alpha_{a}$. Values of $S_{a}, s_{r}$, and $s_{d}$ are obtained from the curves of sensitivity against deflection in figure 6 . 


\section{APPENDIX II}

\section{Phase Difference Between the Fixed-Coil Current and the Quadrant Voltage on the Electrometer and the Relation of This Phase Difference to $\theta$, the Phase Angle Between $E$ and $I$}

The diagram in figure 9 shows the connections of the wattmeter and the electrometer for measuring the power $E I \cos \theta$. The first step is to derive the relation between $I$ and $E_{c}$ or $E_{b}$ in terms of the known constants of the apparatus. By inspection of the diagram and using the notation given under it, the following equation can be written

$$
I_{t}\left(R_{t}+j \omega L_{t}\right)=-I_{t} 2 r+\left(I-I_{t}\right)(R+j \omega L) .
$$

The currents in this equation are all complex quantities, but $I$ may be assumed to have no imaginary component. By equating the real and imaginary components of eq 3 and solving for the two components of $I_{t}$, these may be substituted in

to obtain:

$$
E_{1}=I_{t}\left(R_{t}+j \omega L_{t}\right)
$$

$$
\begin{aligned}
E_{1}= & I\left\{\frac{\left(R_{t} R-\omega^{2} L_{t} L\right)\left(R_{t}+R+2 r\right)+\left(\omega L R_{t}+\omega L_{t} R\right)\left(\omega L_{1}+\omega L\right)}{\left(R_{t}+R+2 r\right)^{2}+\left(\omega L+\omega L_{t}\right)^{2}}\right. \\
& \left.\frac{+j\left[\left(\omega L_{t} R+\omega L R_{t}\right)\left(R_{t}+R+2 r\right)+\left(\omega^{2} L_{t} L-R_{t} R\right)\left(\omega L_{t}+\omega L\right)\right]}{\left(R_{t}+R+2 r\right)^{2}+\left(\omega L+\omega L_{t}\right)^{2}}\right\} .
\end{aligned}
$$

For the present work the approximate values of the constants in the above equation are $R=0.4 \mathrm{ohm}, R_{\imath} \geqq 400 \mathrm{ohms}, r=0.03 \mathrm{ohm}, L=30 \times 10^{-9} h, \omega L_{t} \geqq 600$ ohms.

Thus with sufficient accuracy the equation may be reduced to

$$
E_{1}=I R\left[1-(2 r+R) \frac{R_{t}}{R_{t}^{2}+\omega^{2} L_{t}^{2}}+j \frac{\omega L}{R}+j(R+2 r) \frac{\omega L_{t}}{R_{t}^{2}+\omega^{2} L_{t}^{2}}\right]
$$

and putting

$$
g=(2 r+R) \frac{R_{t}}{R_{t}+\omega^{2} L_{t}^{2}}
$$

and

$$
\begin{gathered}
\delta=\sin ^{-1}\left[\frac{\omega L}{R}+(R+2 r) \frac{\omega L_{t}}{R_{t}+\omega^{2} L_{t}^{2}}\right], \\
E_{1}=I R(1-g+j \sin \delta) .
\end{gathered}
$$

If the ratios and phase angles for the transformer are $n_{c}, \beta_{c}$ and $n_{b}, \beta_{b}$ for the $a c$ and $a b$ coils respectively,

$$
E_{c}=n_{c} E_{1}\left(1+j \sin \beta_{c}\right)
$$

and

$$
E_{b}=n_{b} E_{1}\left(1+j \sin \beta_{b}\right) .
$$

Substituting the value of $E_{1}$ given in eq 4 and neglecting the products of the sines of the small angles $\delta, \boldsymbol{\beta}_{c}$, and $\boldsymbol{\beta}_{b}$,

$$
E_{c}=n_{c} I R\left[1-g+j\left(\sin \delta+\sin \beta_{c}\right)\right]
$$

and

$$
E_{b}=n_{b} I R\left[1-g+j\left(\sin \delta+\sin \beta_{b}\right)\right] .
$$

For the connections of the quadrant electrometer shown in figure 9 , if $V_{n}$ is the voltage from the case to needle, $V_{c}$ from case to quadrant $c$, and $V_{b}$ from case to quadrant $b$, the general equation for the torque is

$$
T=\lambda V_{n}^{2}+\rho_{c} V_{c}^{2}+\rho_{b} V_{b}^{2}+\gamma_{c} V_{n} V_{c}+\gamma_{b} V_{n} V_{b}+\eta V_{c} V_{b}+\nu_{n} V_{n}+\nu_{c} V_{c}+\nu_{b} V_{b}+\nu_{0},
$$


where $\lambda, \rho_{c}, \rho_{b}, \gamma_{\epsilon}, \gamma_{b}, \eta, \nu_{n}, \nu_{\epsilon}, \nu_{b}$, and $\nu_{0}$ are constants of the electrometer. Take the mechanical zero to be the reading when $c, b$, and $n$ are all tied to the case, that is, with current circuit open and $S_{1}$ to the right. This makes $\nu_{0}=0$. For a-c work $\nu_{n}, \nu_{c}$, and $\nu_{b}$ can also be ignored, because the mean values of $V_{n}, V_{e}$, and $V_{b}$ over any number of complete cycles is zero. The electrical zero is adjusted by tilting or rotating the needle until no deflection occurs when $S_{1}$ is thrown to the left. This makes $\lambda=0$. With both current and voltage on, the torque then becomes

$$
T_{\mathrm{I}}=\rho_{c} V_{c}^{2}+\rho_{b} V_{b}^{2}+\gamma_{c} V_{n} V_{c}+\gamma_{b} V_{n} V_{b}+\eta V_{c} V_{b} .
$$

The phase angle, $\theta$, between the current and the voltage is adjusted until the average torque becomes zero, that is, until the electrometer reading is the same as its electrical zero, then

$$
\begin{aligned}
0= & \rho_{c} n_{c}^{2} R^{2} I^{2}+\rho_{b} n_{b}^{2} R^{2} I^{2}+\gamma_{c} n_{c} E I R\left[\cos \left(\Theta-\delta-\beta_{c}\right)\right] \\
& -\gamma_{b} n_{b} E I R\left[\cos \left(\Theta-\delta-\beta_{b}\right)\right]-\eta n_{c} n_{b} R^{2} I^{2}
\end{aligned}
$$

With switch $S_{2}$ reversed, that is $E_{c}$ and $E_{b}$ reversed, $\theta$ is again adjusted until the average torque becomes zero. Then

$$
\begin{aligned}
0= & \rho_{c} n_{c}^{2} R^{2} I^{2}+\rho_{b} n_{b}^{2} R^{2} I^{2}-\gamma_{c} n_{c} E I R\left[\cos \left(\Theta^{\prime}-\delta-\beta_{c}\right)\right] \\
& +\gamma_{b} n_{b} E I R\left[\cos \left(\Theta^{\prime}-\delta-\beta_{b}\right)-\eta n_{c} n_{b} R^{2} I^{2} .\right.
\end{aligned}
$$

Subtract eq 8 from eq 7

$$
\begin{gathered}
0=\gamma_{c} n_{c} E I R\left[\cos \left(\Theta-\delta-\beta_{c}\right)+\cos \left(\theta^{\prime}-\delta-\beta_{c}\right)\right] \\
-\gamma_{b} n_{b} E I R\left[\cos \left(\Theta-\delta-\beta_{b}\right)+\cos \left(\Theta^{\prime}-\delta-\beta_{b}\right)\right] .
\end{gathered}
$$

Expanding the cosines in this equation and neglecting the departure from unity of $\cos \left(\delta+\beta_{c}\right), \cos \left(\delta+\beta_{b}\right), \sin \theta$, and $\sin \theta^{\prime}$ since $\delta+\beta_{c}$ or $\delta+\beta_{b}<10$ minutes and $\theta$ or $\theta^{\prime}$ is within 10 minutes of $\pi / 2$

$$
\begin{aligned}
& \gamma_{c} n_{c}\left[\cos \theta+\sin \left(\delta+\beta_{c}\right)+\cos \theta^{\prime}+\sin \left(\delta+\beta_{c}\right)\right] \\
= & \gamma_{b} n_{b}\left[\cos \theta+\sin \left(\delta+\beta_{b}\right)+\cos \theta^{\prime}+\sin \left(\delta+\beta_{b}\right)\right]
\end{aligned}
$$

Since $\gamma_{e}$ very nearly equals $-\gamma_{b}$ and $n_{c}$ nearly equals $n_{b},-\gamma_{c} n_{e}(1+h)$ may be substituted for $\gamma_{b} n_{b}$; then

$\cos \theta+\cos \theta(1+h)+\cos \theta^{\prime}+\cos \theta^{\prime}(1+h)=-2 \sin \left(\delta+\beta_{c}\right)-2\left[\sin \left(\delta+\beta_{b}\right)\right](1+h)$, and this reduces to

$$
\cos \theta+\cos \theta^{\prime}=-\left[\sin \left(\delta+\beta_{c}\right)\right]\left(1-\frac{1}{2} h\right)-\left[\sin \left(\delta+\beta_{b}\right)\right]\left(1+\frac{1}{2} h\right),
$$

Since $\beta_{c}$ nearly equals $\beta_{b}$ the $h$ terms cancel, and dividing by 2 to get the average $\cos \theta$

$$
\frac{\cos \theta+\cos \theta^{\prime}}{2}=-\frac{1}{2} \sin \left(2 \delta+\beta_{c}+\beta_{b}\right) .
$$

This equation yields the average value of the cosine of the angle between current $I$ and voltage $E$, for the two positions of switch $S_{2}$, in terms of the constants of the apparatus in the electrometer circuit. The cosine of this angle can also be obtained from the expression

$$
W=E I \cos \theta,
$$

where $W$ is the average power indicated by the wattmeter for the two positions of switch $S_{2}$. Any difference between the two values of $\cos \theta$ thus obtained is considered to be caused by the wattmeter phase defect, $\tau_{w}$.

Washington, July 25, 1940. 